\title{
Net ecosystem fluxes of isoprene over tropical South America inferred from Global Ozone Monitoring Experiment (GOME) observations of HCHO columns
}

\section{Citation}

Barkley, Michael P., Paul I. Palmer, Uwe Kuhn, Juergen Kesselmeier, Kelly Chance, Thomas P. Kurosu, Randall V. Martin, Detlev Helmig, and Alex Guenther. 2008. "Net Ecosystem Fluxes of Isoprene over Tropical South America Inferred from Global Ozone Monitoring Experiment (GOME) Observations of HCHO Columns." Journal of Geophysical Research 113 (D20). https:// doi.org/10.1029/2008jd009863.

\section{Permanent link}

http://nrs.harvard.edu/urn-3:HUL.InstRepos:41461234

\section{Terms of Use}

This article was downloaded from Harvard University's DASH repository, and is made available under the terms and conditions applicable to Other Posted Material, as set forth at http:// nrs.harvard.edu/urn-3:HUL.InstRepos:dash.current.terms-of-use\#LAA

\section{Share Your Story}

The Harvard community has made this article openly available.

Please share how this access benefits you. Submit a story.

Accessibility 


\title{
Net ecosystem fluxes of isoprene over tropical South America inferred from Global Ozone Monitoring Experiment (GOME) observations of HCHO columns
}

\author{
Michael P. Barkley, ${ }^{1}$ Paul I. Palmer, ${ }^{1}$ Uwe Kuhn, ${ }^{2,3}$ Juergen Kesselmeier, ${ }^{2}$ \\ Kelly Chance, ${ }^{4}$ Thomas P. Kurosu, ${ }^{4}$ Randall V. Martin, ${ }^{4,5}$ Detlev Helmig, ${ }^{6}$ \\ and Alex Guenther ${ }^{7}$ \\ Received 24 January 2008; revised 17 June 2008; accepted 22 July 2008; published 17 October 2008.
}

[1] We estimate isoprene emissions over tropical South America during 1997-2001 using column measurements of formaldehyde (HCHO) from the Global Ozone Monitoring Experiment (GOME) satellite instrument, the GEOS-Chem chemistry transport model, and the MEGAN (Model of Emissions of Gases and Aerosols from Nature) bottom-up isoprene inventory. GEOS-Chem is qualitatively consistent with in situ ground-based and aircraft concentration profiles of isoprene and $\mathrm{HCHO}$, and GOME HCHO column data $(\mathrm{r}=0.41$; bias $=+35 \%)$, but has less skill in reproducing wet season observations. Observed variability of GOME HCHO columns over South America is determined largely by isoprene and biomass burning. We find that the column contributions from other biogenic volatile organic compounds (VOC) are typically smaller than the column fitting uncertainty. HCHO columns influenced by biomass burning are removed using Along Track Scanning Radiometer (ATSR) firecounts and GOME $\mathrm{NO}_{2}$ columns. We find that South America can be split into eastern and western regions, with fires concentrated over the eastern region. A monthly mean linear transfer function, determined by GEOS-Chem, is used to infer isoprene emissions from observed HCHO columns. The seasonal variation of GOME isoprene emissions over the western region is broadly consistent with MEGAN ( $\mathrm{r}=0.41$; bias $=-25 \%$ ), with largest isoprene emissions during the dry season when the observed variability is consistent with knowledge of temperature dependence. During the wet season, other unknown factors play a significant role in determining observed variability.

Citation: Barkley, M. P., P. I. Palmer, U. Kuhn, J. Kesselmeier, K. Chance, T. P. Kurosu, R. V. Martin, D. Helmig, and A. Guenther (2008), Net ecosystem fluxes of isoprene over tropical South America inferred from Global Ozone Monitoring Experiment (GOME) observations of HCHO columns, J. Geophys. Res., 113, D20304, doi:10.1029/2008JD009863.

\section{Introduction}

[2] Tropical terrestrial ecosystems are a significant source of biogenic volatile organic compounds (BVOCs). The dominant nonmethane BVOC is isoprene $\left(\mathrm{C}_{5} \mathrm{H}_{8}\right)$, which represents almost half of the global annual nonmethane VOC flux [Guenther et al., 1995, 2006]. Tropical ecosystems contribute nearly $75 \%$ of the global atmospheric isoprene

\footnotetext{
${ }^{1}$ School of GeoSciences, University of Edinburgh, Edinburgh, UK.

${ }^{2}$ Biogeochemistry Department, Max Planck Institute for Chemistry, Mainz, Germany.

${ }^{3}$ Now at Agroscope Reckenholz-Taenikon Research Station, Zurich, Switzerland.

${ }^{4}$ Atomic and Molecular Physics Division, Harvard-Smithsonian Center for Astrophysics, Cambridge, Massachusetts, USA.

${ }^{5}$ Department of Physics and Atmospheric Science, Dalhousie University, Halifax, Nova Scotia, Canada.

${ }^{6}$ INSTAAR, University of Colorado, Boulder, Colorado, USA.

${ }^{7}$ Biosphere-Atmosphere Interactions Group, Atmospheric Chemistry Division, NCAR, Boulder, Colorado, USA.
}

Copyright 2008 by the American Geophysical Union. 0148-0227/08/2008JD009863\$09.00 budget [Guenther et al., 2006], reflecting a year-long growing season, warm temperatures, and high solar insolation. The high VOC loading and favorable atmospheric conditions (high concentrations of the hydroxyl radical, $\mathrm{OH}$ ) ensures that the tropics also exert considerable influence on global tropospheric photochemistry [Andreae and Crutzen, 1997]. Isoprene has a strong influence on the oxidation capacity of the atmospheric boundary layer [Poisson et al., 2000; Monson and Holland, 2001], and can contribute to the formation of tropospheric ozone [Wang and Shallcross, 2000; Sanderson et al., 2003] and be a precursor of secondary organic aerosol [Claeys et al., 2004; Henze and Seinfeld, 2006], thereby playing a significant role in determining Earth's climate. Isoprene emissions also represent a significant loss of fixed carbon from the terrestrial biosphere, relative to the net biome productivity [Kesselmeier et al., 2002a].

[3] Global and regional isoprene emissions, determined by bottom-up models constrained by sparse in situ data, are poorly known [Guenther et al., 1995, 2006; Potter et al., 
Table 1. Estimates and Direct Measurements of Isoprene Fluxes Within the Tropical Amazon Rain Forest

\begin{tabular}{|c|c|c|c|}
\hline Study & $\begin{array}{l}\text { Isoprene Flux } \\
\left(\mu \mathrm{g} \mathrm{m}^{-2} \mathrm{~h}^{-1}\right)\end{array}$ & Location & Comment \\
\hline Jacob and Wofsy $[1988]^{\mathrm{a}}$ & 1580 & Duke forest reserve, $10 \mathrm{~km}$ north of Manaus, Brazil & Average flux (0800-1800 LT) \\
\hline Davis et al. [1994] $]^{\mathrm{a}}$ & $3630 \pm 1400$ & Duke forest reserve, $10 \mathrm{~km}$ north of Manaus, Brazil & Average flux $(0800-1500 \mathrm{LT})$ \\
\hline Helmig et al. [1998] & $3000-8200$ & $\sim 500 \mathrm{~km}$ west of Iquitos, Peru & Average flux $(1000-1800 \mathrm{LT})$ \\
\hline Rinne et al. [2002] & 2400 & Floresta Nacional do Tapajos, Para, Brazil & $\begin{array}{l}\text { Normalized flux } \\
\left(\mathrm{T}=30^{\circ} \mathrm{C}, \mathrm{PAR}=1100 \mu \mathrm{mol} \mathrm{m}^{-2} \mathrm{~s}^{-1}\right)\end{array}$ \\
\hline Greenberg et al. [2004] & $\begin{array}{l}5300 \\
9800 \\
2200\end{array}$ & $\begin{array}{l}\text { Balbina, } 150 \mathrm{~km} \text { north of Manaus, Brazil } \\
\text { Reserva Biologica do Jaru, Rondonia, Brazil } \\
\text { Tapajos Forest, Para, Brazil }\end{array}$ & Maximum flux \\
\hline Kuhn et al. [2007] & $2380 \pm 1800$ & K34 tower $60 \mathrm{~km}$ NNW of Manaus, Brazil & Average flux (1000-1500 LT) \\
\hline Karl et al. [2007] & $7800 \pm 2300$ & $60 \mathrm{~km}$ NNW of Manaus, Brazil & Average noon flux \\
\hline
\end{tabular}

${ }^{\mathrm{a}}$ The Jacob and Wofsy [1988] and Davis et al. [1994] estimates were determined from the same observational data set.

2001; Purves et al., 2004]. Bottom-up isoprene models extrapolate in situ point concentration and/or exchange/flux measurements to regional and continental scales using forestry inventory data and satellite based land cover. The extrapolation from point measurements to the observed spectra of plant species, age and growing conditions is difficult especially where ecosystem diversity is high, for example, tropical rainforests. Parameterized variability of isoprene fluxes due to changing environmental conditions, such as temperature and photosynthetic active radiation (PAR), are determined using empirical algorithms that have been developed largely from greenhouse measurements of vegetation indigenous to the midlatitudes. Bottom-up emissions are consequently most accurate over temperate regions (of order $50 \%$ uncertainty), where most in situ measurement campaigns have occurred, and least reliable over tropical latitudes where data are sparse owing in part to inaccessibility.

[4] Here we focus on BVOC emissions over tropical South America, particularly over the Amazon Basin. Over this region, measured daytime isoprene emission rates range from 1500 to $9800 \mu \mathrm{g} \mathrm{m}^{2} \mathrm{~h}^{-1}$ (see Table 1), with significant unexplained differences between the wet and dry seasons [Kuhn et al., 2004b]. We loosely define the wet and dry seasons (on a continental scale) as December-May and August-November, respectively, while acknowledging regional and interannual variability [Liebmann and Marengo, 2001]. Without significant additional sampling of isoprene fluxes and concentrations over this region (and the tropics in general) bottom-up isoprene emission inventories will remain quantitatively unreliable on regional and continental scales.

[5] In this paper we explore the top-down constraints on isoprene emissions over tropical South America from satellite column measurements of formaldehyde (HCHO) from the Global Ozone Monitoring Experiment (GOME) [Chance et al., 2000; Palmer et al., 2001, 2003, 2006]. Formaldehyde is a high-yield product of VOC oxidation. Its atmospheric abundance is determined by the balance between production from the oxidation of VOCs and losses from oxidation by $\mathrm{OH}$ and photolysis, leading to a lifetime of a few hours. Formaldehyde columns measured from space therefore provide constraints on the reactive VOC emissions. In the remote atmosphere, the oxidation of $\mathrm{CH}_{4}$ provides a relatively uniform concentration of $\mathrm{HCHO}$ but in the continental planetary boundary layer the oxidation of short-lived VOCs significantly enhance HCHO above the $\mathrm{CH}_{4}$ uniform background. Previous studies using GOME
HCHO data have focused on North America and eastern Asian and showed that isoprene is largely responsible for observed variability in HCHO columns during summertime [Palmer et al., 2003, 2006; Abbot et al., 2003; Millet et al., 2006; Fu et al., 2007]. Shim et al. [2005] used the GEOS-Chem chemistry transport model (CTM) [Bey et al., 2001] driven by GEOS-STRAT meteorological data [Schubert et al., 1993] and biogenic emissions from the Global Emission Inventory Activity (GEIA) database [Guenther et al., 1995] to conduct a global inversion of GOME HCHO column data from 1996 to 1997 and showed that over South America the model HCHO columns correlated reasonably well with the data $(r=0.6)$; from that correlation they estimated isoprene emissions of $106 \mathrm{Tg} \mathrm{C} / \mathrm{a}$ for that region.

[6] Biomass burning is a significant source of HCHO over the tropics, and we pay particular attention to removing this contribution from observed variability of $\mathrm{HCHO}$ columns by using GOME measurements of nitrogen dioxide $\left(\mathrm{NO}_{2}\right)$ and firecounts from the Along-Track Scanning Radiometer (ATSR) on board the ERS-2 spacecraft. Here we present the first interpretation of the seasonal and interannual variability of $\mathrm{HCHO}$ over South America and use these data to infer BVOC emissions, taking into account the distinct wet and dry seasons over this region. Resulting BVOC emissions inferred from GOME represent net canopy-atmosphere fluxes that are directly applicable to (1) CTMs that do not include a detailed treatment of withincanopy chemistry and physics, and (2) flux measurements made above the forest canopy.

[7] In the next section we describe the GOME column data and discuss the approach we adopt to identify and remove the biomass burning contributions to observed $\mathrm{HCHO}$ column variability. In section 3, we briefly describe the GEOS-Chem CTM and the MEGAN isoprene emission inventory. In section 4, we use ground-based and airborne profiles of isoprene and $\mathrm{HCHO}$ over South America to evaluate MEGAN and GEOS-Chem. In section 5 we detail the method used to infer isoprene emissions from HCHO columns and present an error analysis of resulting top-down isoprene emissions. In section 6 we discuss differences between the top-down GOME and bottom-up MEGAN isoprene emissions, and conclude the paper in section 7 .

\section{HCHO Columns From the GOME Instrument}

\subsection{Retrieval of HCHO Vertical Columns}

[8] The GOME instrument, a passive UV-Vis nadirviewing spectrometer, measures sunlight scattered by the 
atmosphere and/or reflected from the surface, covering the spectral range $240-790 \mathrm{~nm}$ at moderate spectral resolution (0.2-0.4 nm) [Burrows et al., 1999]. It was launched in April 1995 aboard the ERS-2 spacecraft into a polar Sunsynchronous orbit (100 min period) crossing the Equator, on its descending node, at 1030 local time (LT), achieving global coverage within 3 days. GOME makes three (eastwest) forward scans, each with a spatial resolution of $40 \times$ $320 \mathrm{~km}^{2}$, and a back scan; we do not use the back scan data in this study. Here, we outline the three-step methodology adopted to determined vertical columns of HCHO.

[9] 1. Slant columns of $\mathrm{HCHO}$ are retrieved by directly fitting radiances at 336-356 $\mathrm{nm}$ [Chance et al., 2000]. The mean fitting uncertainty is $4 \times 10^{15}$ molec $\mathrm{cm}^{-2}$, but a possible $+17 \%$ bias in the retrieval exists because of errors in the HCHO absorption cross section [Fu et al., 2007; Gratien et al., 2007].

[10] 2. Spectral artifacts introduced by the instrument diffuser plate degrade the quality of the measured solar irradiance spectra creating a bias in the retrieved slant columns that varies according the solar reference spectra used [Richter and Wagner, 2001; Palmer et al., 2003, 2006; Shim et al., 2005]. This bias is estimated and removed by attributing it to the difference between observed and model $\mathrm{HCHO}$ columns over the remote Pacific, where HCHO is determined largely by $\mathrm{CH}_{4}$ oxidation and relatively well understood. We account for the latitudinal and scan angle dependence of the diffuser plate bias, following Palmer et al. [2006], and discard orbital data corrupted by poor quality solar radiance spectra. These data quality steps discard approximately $30 \%$ of GOME retrievals but effectively removes anomalous features from the observed distributions.

[11] 3. Vertical columns are calculated from slant columns using air mass factors (AMFs) that account for Rayleigh, aerosol and cloud scattering, and surface albedo [Palmer et al., 2001, 2003; Martin et al., 2002]. By including scattering into the AMF calculation the AMF becomes sensitive to the vertical distribution of the atmospheric species being studied (shape factor), which we determine using the GEOS-Chem CTM. We use the LIDORT radiative transfer model for the radiative transfer calculations (scattering weights) [Spurr et al., 2001]. Cloud information for each GOME observation is retrieved using the GOMECAT algorithm [Kurosu et al., 1999], which uses the Polarization Measurement Devices (PMDs) to determine cloud fraction, and $\mathrm{O}_{2} A$ band radiances to retrieve cloud top pressure and optical thickness. Scenes that have cloud coverage $>40 \%$ are excluded. Using a stricter cloud threshold does not significantly affect the GOME HCHO column statistics. The UV surface albedo is taken from a climatological database constructed from over 5 years of GOME measurements [Koelemeijer et al., 2003].

[12] Clouds are the main source of uncertainty in the AMF calculation, estimated to create errors of $20-30 \%$ [Martin et al., 2002; Millet et al., 2006]. AMF errors from uncertainties in the $\mathrm{HCHO}$ shape factor, albedo and aerosols are smaller $(<10 \%)$, unless the aerosol loading is very high, for example, biomass burning scenes [Palmer et al., 2006; Millet et al., 2006]. Under such conditions the AMF becomes much more sensitive to the relative vertical distributions of the aerosols and the HCHO [Fu et al.,
2007]. The total error on the HCHO AMF is estimated to be $\sim 30 \%$ [Palmer et al., 2006].

[13] Previous studies have calculated monthly mean AMFs from a single model year and applied them to the entire GOME data set [e.g., Abbot et al., 2003; Palmer et al., 2006; Fu et al., 2007]. In this analysis, we compute AMFs for each individual GOME scene (1997-2001) using GEOS-Chem (daily) HCHO and (monthly) aerosols fields simulated for the nominal year 2000 (see section 4.2). The variation in the calculated monthly mean AMFs over tropical South America during 1997-2001 is small (not shown), varying between $0.92-1.12$. Interannual variability is negligible.

\subsection{Separation of Biogenic and Pyrogenic HCHO}

[14] Figure 1 shows the monthly mean GOME HCHO slant column distributions over tropical South America for 1997-2001, averaged on to the GEOS-Chem $2^{\circ} \times 2.5^{\circ}$ horizontal grid. The $\mathrm{HCHO}$ distributions exhibit a seasonal cycle with observed columns highest $\left(>3 \times 10^{16} \mathrm{molec} / \mathrm{cm}^{-2}\right)$ during August-October over central Brazil, reflecting seasonal burning during the dry season; outside this period the HCHO columns are much lower. In addition, the columns are particularly noisy over southeastern Brazil, compared with other regions, as they are affected by the South Atlantic Anomaly (SAA) [Heirtzler, 2002]. The SAA is an anomalous weak area of the Earth's geomagnetic field where trapped energetic charged particles cause damage to satellite components [Stassinopoulos and Raymond, 1988]. The SAA degrades all GOME trace gas retrievals throughout the year, with HCHO slant column uncertainties on average $60 \%$ greater than elsewhere.

[15] $\mathrm{HCHO}$ is released into the atmosphere by incomplete combustion, directly from emissions from fuel combustion and indirectly from the oxidation of coemitted VOCs [Lee et al., 1998; Andreae and Merlet, 2001]; the magnitude of both primary and secondary $\mathrm{HCHO}$ sources are extremely uncertain and are not the subject of this study. Here, we aim to identify and subsequently remove the burning contribution to observed HCHO columns. Figure 2 demonstrates the strong spatial correlation between GOME HCHO and active fires detected by the ATSR instrument aboard the ERS-2 spacecraft with GOME. We also show GOME vertical columns of $\mathrm{NO}_{2}$ [Martin et al., 2002] that are largely determined by biomass burning over South America [Martin et al., 2003; Jaeglé et al., 2005]. The information used to calculate $\mathrm{NO}_{2}$ AMFs is consistent with that used for $\mathrm{HCHO}$ in this paper. Estimated monthly mean $\mathrm{NO}_{2}$ vertical column uncertainties over land are $5-8 \times 10^{14}$ molec $\mathrm{cm}^{-2}$ [Martin et al., 2002, 2003]. There is a good correspondence between $\mathrm{NO}_{2}$ columns and the firecounts, despite ATSR and GOME measurements being taken at different times, providing confidence in our approach of using these data to identify $\mathrm{HCHO}$ from biomass burning. Spatial distributions of $\mathrm{HCHO}, \mathrm{NO}_{2}$ and active firecounts show two distinct regions: an eastern region where biomass burning events are widespread (especially during the dry season), and a western area where fires are much less frequent. The SAA also compromises quantitatively interpretation of $\mathrm{HCHO}$ columns over the eastern most South America. For the purpose of this paper we concentrate our study over the 

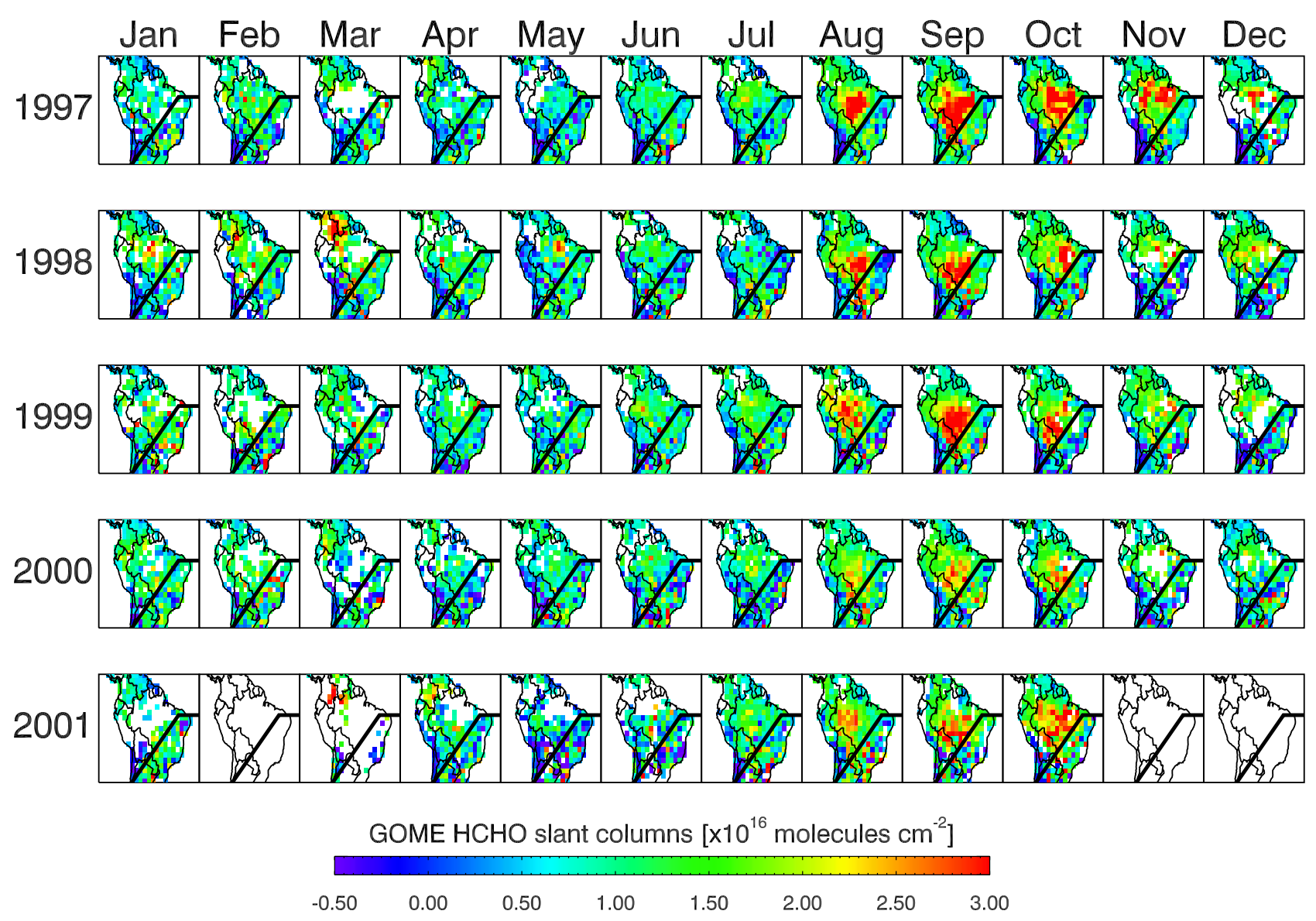

Figure 1. Monthly mean GOME HCHO slant columns $\left(\right.$ molec $\left.\mathrm{cm}^{-2}\right)$ over tropical South America for January-December 1997-2001, averaged on the GEOS-Chem $2^{\circ} \times 2.5^{\circ}$ grid. The GOME data are for $1000-1200$ local time (LT) and correspond to observations with cloud cover $\leq 40 \%$. No measurements are available for February, November, and December of 2001. HCHO column data southeast of the black line are compromised by the South Atlantic Anomaly (section 2.2).

western region where we remove the residual burning signal from the observed $\mathrm{HCHO}$ columns.

[16] Figure 3 shows the corresponding time series of the monthly mean $\mathrm{HCHO}$ slant columns and $\mathrm{NO}_{2}$ vertical columns over the eastern region defined by Figure 2 where there is active burning. There is a strong temporal correlation $(\mathrm{r}=0.8)$ as the amount of $\mathrm{HCHO}$ and $\mathrm{NO}_{2}$ in the atmosphere peaks about 1-2 months after the maximum frequency in active fires (which typically occurs at the beginning of August). Enhanced HCHO production from elevated isoprene emissions during August-October (when temperatures and light levels are highest) and release of $\mathrm{HCHO}$ from smouldering fires will contribute to this slight phase lag [Yokelson et al., 1997]. Sampling and instrumental issues associated with the firecount data, such as nighttime measurements and inclusion of nonvegetation fires [Mota et al., 2006], will also likely contribute to this phase difference.

[17] We adopt a two-step approach to ensure that pyrogenic contributions to observed HCHO columns are removed from subsequent analysis of GOME data. First, the ATSR firecount data are mapped on to the GEOS-Chem grid $\left(2^{\circ} \times 2.5^{\circ}\right)$, and $\mathrm{HCHO}$ data falling in grid points where there is active fire are excluded from subsequent analysis. We recognize the shortcomings of the firecount data [Mota et al., 2006] but they nevertheless provide valuable information on the location and frequency of active fires. Second, we use elevated $\mathrm{NO}_{2}$ columns as a marker of biomass burning to discard corresponding $\mathrm{HCHO}$ columns. We use the 1997-2001 monthly mean time series of $\mathrm{NO}_{2}$ columns (Figure 3) to determine a column threshold, above which indicates biomass burning. Within the burning season, defined here as August-November, both the $\mathrm{HCHO}$ and $\mathrm{NO}_{2}$ peak simultaneously. The mean $\mathrm{NO}_{2}$ during this season is $1.2 \times 10^{15}$ molec $\mathrm{cm}^{-2}$, whilst in the rest of the year it is less than half this value. We employ $\mathrm{a} \mathrm{NO}_{2}$ threshold of $0.8 \times 10^{15}$ molec cm $\mathrm{cm}^{-2}$, determined by the time series. Outside the burning season the monthly mean $\mathrm{NO}_{2}$ columns rarely exceed this threshold level.

\section{Modeling HCHO Columns Over Tropical South America}

\subsection{GEOS-Chem Chemistry Transport Model} Framework

[18] GEOS-Chem is a global 3-D chemistry transport model (v7.04), applied here to simulate $\mathrm{O}_{3}-\mathrm{NO}_{\mathrm{x}}-\mathrm{VOC}$ aerosol for the interpretation of $\mathrm{HCHO}$ columns from the GOME instrument. The model is forced with assimilated meteorological data from the Goddard Earth Observing 

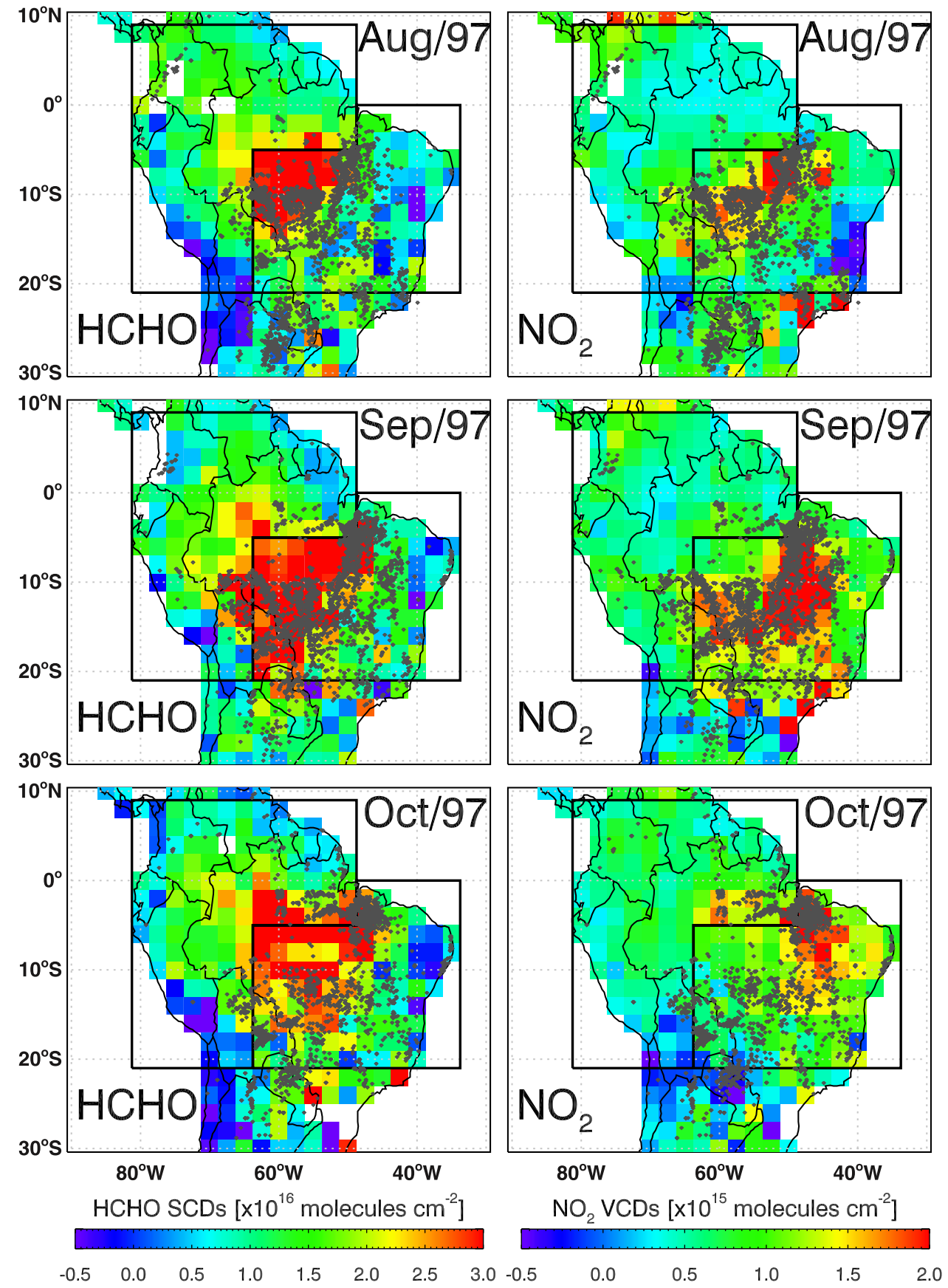

Figure 2. Monthly mean (left) GOME HCHO slant columns and (right) GOME $\mathrm{NO}_{2}$ vertical columns averaged on the GEOS-Chem $2^{\circ} \times 2.5^{\circ}$ grid for August-October 1997. Active burning, detected by the ATSR instrument, is shown by grey diamonds. The distinct fire spatial distributions allow tropical South America to be split into an eastern region where biomass burning is very common, and a western region where wild fires are less prominent (black boxes).

System (GEOS-4) of the NASA Global Modelling and Assimilation Office (GMAO) [Bey et al., 2001]. The GEOS-4 data have a 6-hour temporal resolution (3-hour for surface variables and mixing depths) and a $1^{\circ} \times 1.25^{\circ}$ horizontal resolution. There are 55 hybrid eta levels that extend from the surface to $0.01 \mathrm{hPa}$. The boundary layer up to $2 \mathrm{~km}$ is resolved by 5 layers with midpoints at 58,249 , 615,1197 and $1986 \mathrm{~m}$ for a column based at sea level. We use the model at $2^{\circ} \times 2.5^{\circ}$ horizontal grid and with 30 eta levels, with levels above $\sim 50 \mathrm{hPa}$ lumped together.
[19] The chemistry mechanism, based on work by Horowitz et al. [1998], has approximately 80 species and 300 reactions, and includes modifications by Bey et al. [2001], Fiore et al. [2002], Martin et al. [2003] and Park et al. [2004]. It includes a detailed representation of oxidation pathways for five nonmethane hydrocarbons (ethane, propane, lumped $>\mathrm{C}_{3}$ alkanes, lumped $>\mathrm{C}_{2}$ alkenes and isoprene). Under low $\mathrm{NO}_{\mathrm{x}}$ conditions $(<0.1 \mathrm{ppb})$, as typically found in tropical ecosystems away from regions of burning [Jacob and Bakwin, 1992; Andreae et al., 


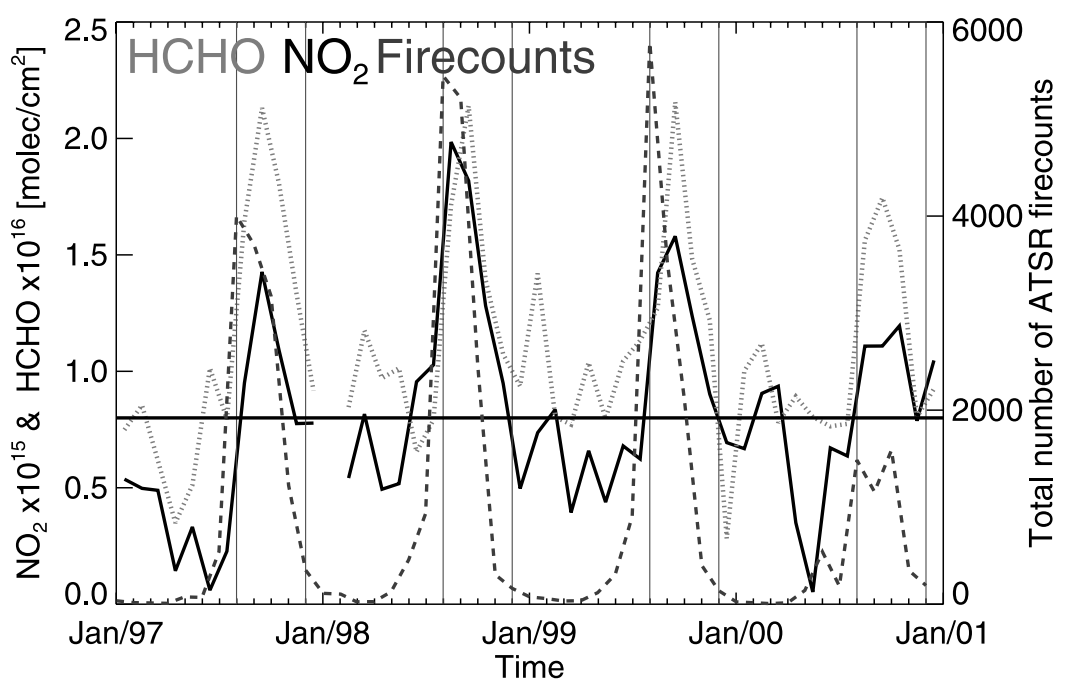

Figure 3. Time series of the monthly mean gridded GOME HCHO slant columns (dotted light grey line) and GOME $\mathrm{NO}_{2}$ vertical columns (solid black line), over the eastern region during 1997-2001, calculated using only grid squares in which wild fires occur. The corresponding total number of ATSR firecounts is shown by the dashed dark grey line. The $\mathrm{NO}_{2}$ threshold of $0.8 \times 10^{15}$ molec cm ${ }^{-2}$ used to identify biomass burning is shown as the solid horizontal black line. The beginning (August) and end (November) of the burning season is indicated by the solid vertical black lines.

2002], the HCHO molar yields predicted by GEOS-Chem and the Master Chemical Mechanism (MCM v3.01) [Bloss et al., 2005] after 1 day, are 0.95 and 1.6 respectively, comprising $66 \%$ and $68 \%$ of their ultimate $\mathrm{HCHO}$ yields [Palmer et al., 2006]. This provides confidence that we can relate observed $\mathrm{HCHO}$ column variability to emissions of isoprene under low $\mathrm{NO}_{\mathrm{x}}$ conditions. However, these model $\mathrm{HCHO}$ yields from isoprene oxidation at low $\mathrm{NO}_{\mathrm{x}}$ concentrations are considerably uncertain, reflecting current uncertainties in the chemistry. Production of HCHO from $\alpha$-and $\beta$-pinenes and methylbutenol (MBO) are parameterized using MCM calculations [Palmer et al., 2006]. Previous studies of $\mathrm{HCHO}$ columns over North America showed that $\mathrm{HCHO}$ columns from monoterpenes and $\mathrm{MBO}$ were indistinguishable from noise in the column measurements [Palmer et al., 2006]. We assessed the contribution of monoterpenes and $\mathrm{MBO}$ to $\mathrm{HCHO}$ columns over tropical South America by performing a sensitivity simulation without their HCHO production. Similarly, we find their emissions contribute only a small fraction of the $\mathrm{HCHO}$ column (not shown), comparable in magnitude to the spectral fitting uncertainty of GOME HCHO columns.

\subsection{Emissions Inventories}

[20] Biomass burning emissions, for 15 species including $\mathrm{HCHO}$, are from the Global Fire Emission Database version 2 (GFEDv2) [Giglio et al., 2003, 2006; van der Werf et al., 2006]. The GFED inventory uses $1^{\circ} \times 1^{\circ}$ monthly carbon emissions $\left(\mathrm{g} \mathrm{C} \mathrm{m}^{-2}\right)$, determined using satellite firecount data and the CASA biogeochemical model [Potter et al., 1993], that are scaled by tracer specific emissions factors [Andreae and Merlet, 2001], as a function of vegetation type, to produce an estimate of that tracer's biomass burning emissions (which are subsequently regridded to the GEOS-Chem grid). During 1997-2001 GFED estimates of global emissions of HCHO are $1.55-2.81 \mathrm{Tg} \mathrm{C}$, of which $0.13-0.35 \mathrm{Tg} \mathrm{C}$ originates from the eastern and western regions over tropical South America (Figure 2). Anthropogenic emissions are described by Park et al. [2004].

[21] Biogenic emissions of isoprene, monoterpenes and methylbutenol (MBO) are based on the Model of Emissions of Gases and Aerosols from Nature (MEGAN) [Guenther et al., 2006]. Emissions of limonene, a BVOC with a potentially large but unquantified $\mathrm{HCHO}$ timedependent yield, are not considered in this study as they only comprise $2-10 \%$ of the total monoterpene species over the Amazon Basin [Kesselmeier et al., 2000, 2002b].

[22] MEGAN contains significant improvements to the base emission factors and driving algorithms in relation to the GEIA inventory [Guenther et al., 1995]. Isoprene emissions $E$ in MEGAN are parameterized as

$$
E=E_{0} \times \gamma_{T} \times \gamma_{P A R} \times \gamma_{L A I} \times \gamma_{A g e} \times \gamma_{S M} \times \rho,
$$

where $E_{0}$ is the baseline emission factor for standard conditions (in $\mathrm{mg}$ of isoprene $\mathrm{m}^{-2} \mathrm{~h}^{-1}$ ), which is adjusted to the local environmental conditions by dimensionless "activity" factors that correct for variations in leaf temperature $\gamma_{T}$ (as a function both of the current temperature and the average over the last 15 days), photosynthetically active radiation (PAR) $\gamma_{P A R}$, leaf area index $\gamma_{L A I}$, leaf age $\gamma_{A g e}$ and soil moisture $\gamma_{S M}$. Each of the activity factors are normalized to standard conditions (air temperature $=303 \mathrm{~K}$, PAR $=1500 \mu \mathrm{mol} \mathrm{m} \mathrm{m}^{-2} \mathrm{~s}^{-1}$, leaf area index $=5$, soil moisture $=0.3 \mathrm{~m}^{3} \mathrm{~m}^{-3}$ ). The effect of soil moisture $\gamma_{S M}$ is not taken into account in the current GEOS-Chem implementation of MEGAN. A recent study has shown that $\gamma_{S M}$ is close to unity over tropical South America throughout the year [Müller et al., 2008]. Isoprene production and losses within the vegetation canopy itself, represented by the normalized ratio $\rho$, are also not implemented (i.e., $\rho=1$ ). 
Table 2. Summary of the Validation Data Used to Assess GEOS-Chem

\begin{tabular}{|c|c|c|c|c|c|}
\hline Location & $\begin{array}{c}\text { Rainforest } \\
\text { Type }\end{array}$ & $\begin{array}{c}\text { Species } \\
\text { Measured }\end{array}$ & $\begin{array}{l}\text { Sampling } \\
\text { Period }\end{array}$ & $\begin{array}{l}\text { Sampling } \\
\text { Platform }^{\mathrm{a}}\end{array}$ & Reference \\
\hline st of Iquitos, Peru & Primary & Isoprene & July 1996 & Tethered Balloon & Helmig et al. [1998] \\
\hline Tapajós National Forest, Brazil & Primary & Isoprene & 2002 & Tower $(\sim 59 \mathrm{~m})$ & Trostdorf et al. [2004] \\
\hline $60 \mathrm{~km}$ NNW of Manaus, Brazil & Mature & Isoprene & July 2001 & Aircraft & Kuhn et al. [2007] \\
\hline Tower A, Rebio Jaru, Rondonia, Brazil & Primary & $\mathrm{HCHO}$ & May, Oct 1999 & Tower $(24-52 \mathrm{~m})$ & Kesselmeier et al. $[2002 \mathrm{~b}]$ \\
\hline IBAMA, Rebio Jaru, Rondonia, Brazil & Secondary & $\mathrm{HCHO}$ & May, Oct 1999 & Scaffold $(8-10 \mathrm{~m})$ & Kesselmeier et al. $[2002 \mathrm{~b}]$ \\
\hline
\end{tabular}

${ }^{a}$ The sampling heights for the towers and scaffold are shown in brackets.

[23] In standard GEOS-Chem simulations, the baseline MEGAN isoprene emission factors are regridded from $1^{\circ} \times$ $1^{\circ}$ to the GEOS-Chem horizontal resolutions and driven by 3-hourly surface air temperatures (at $2 \mathrm{~m}$ height), and by diffuse and direct PAR from GEOS-4. Variations in LAI are based on monthly mean values for the year 2000, derived from the Advanced Very High Resolution Radiometer (AVHRR) [Myneni et al., 1997].

\section{Model Evaluation}

[24] In this section, we evaluate the ability of MEGAN and GEOS-Chem to reproduce observed isoprene and HCHO concentrations from aircraft [Kuhn et al., 2007], balloon [Helmig et al., 1998], and tower [Kesselmeier et al., 2002b; Trostdorf et al., 2004] platforms over tropical South America (validation data are summarized in Table 2; measurement locations are shown in Figure 4). The reader should be aware that the balloon measurements of Helmig et al. [1998] have been used to construct the MEGAN isoprene emission inventory over South America. To provide the reader with some idea of the uncertainty associated with regional modeling of isoprene emissions we have included in this section four model runs that use different versions of MEGAN and different temperature fields to drive MEGAN.

[25] 1. MEGAN v2004 uses base emission factors $E_{0}$, downloaded from the National Centre for Atmospheric Research (NCAR) website in 2004 (referenced online as MEGANv1; http:/bai.acd.ucar.edu/Megan/index.shtml), driven by the air temperature $2 \mathrm{~m}$ above the surface, $T(0)$. The v2004 map is based on 7 field studies conducted in the Amazon between 1979 and 2000 [Guenther et al., 2006].

[26] 2. MEGAN v2004 T(1) is the same as MEGAN v2004 but is driven by temperature in the first model layer, $T(1)$. Mature rainforest canopies can be as high at $40-50 \mathrm{~m}$, which is comparable with the thickness of the first GEOS-Chem model layer $(\sim 100 \mathrm{~m}) . T(1)$ is on average $1.6 \mathrm{~K}$ lower than $T(0)$, and represent a 6-hour average instead of a 3-hour average.

[27] 3. MEGAN v2006 uses base emission factors downloaded from NCAR in 2006 (referenced online as MEGANv2), driven by the surface air temperature. The v2006 emission factors are based on the original v2004 map, but include updates from (1) an additional 5 studies conducted between 2000 and 2004 in Amazonia and the Guyanas, and (2) more recent vegetation distribution maps that indicate a high fraction of isoprene emitting species (e.g.,

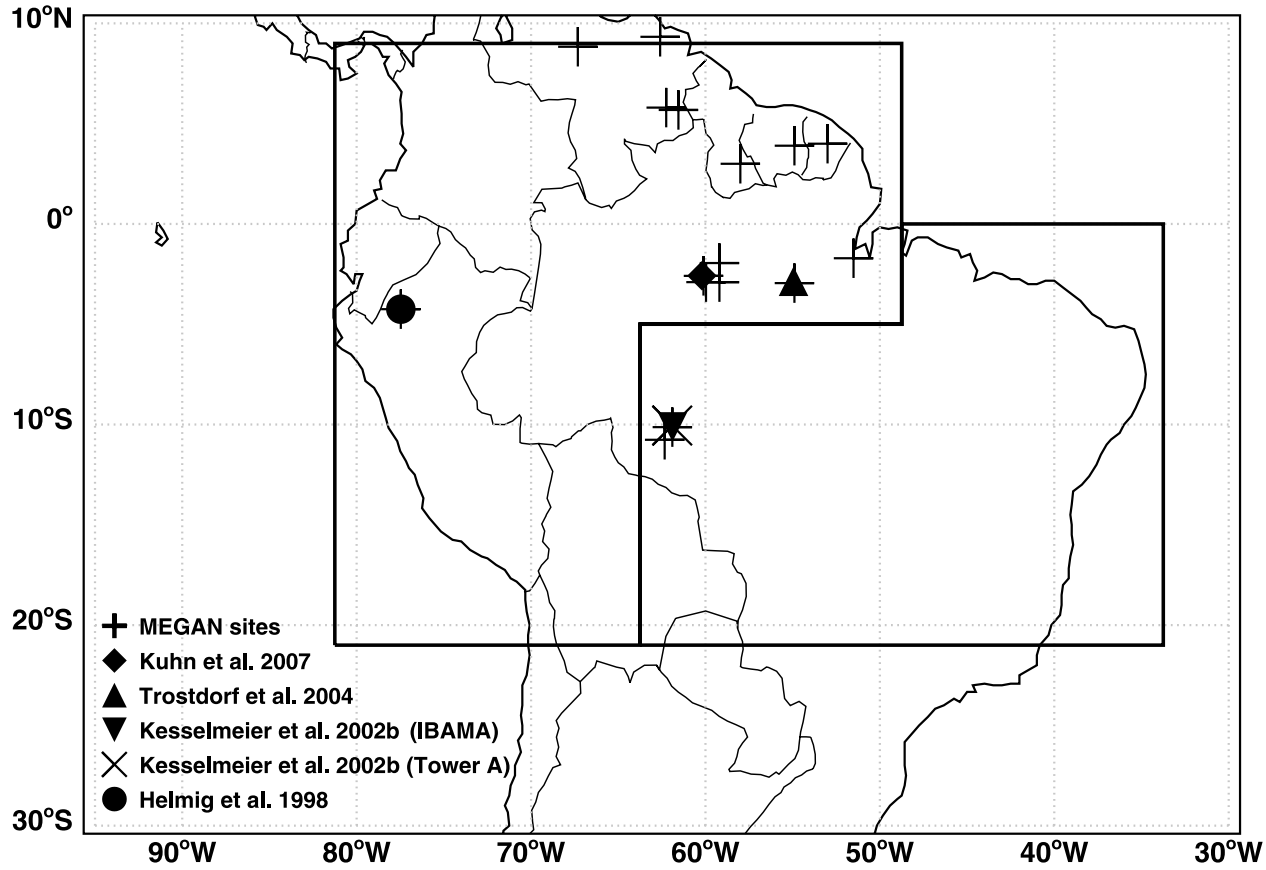

Figure 4. Site locations of the in situ measurements (symbols) used to validate GEOS-Chem (section 4) and to construct the MEGAN bottom-up inventory [Guenther et al., 2006] (black orthogonal crosses). The solid black line represents the division between the east and west regions defined in Figure 2. 
MEGAN (v2004)

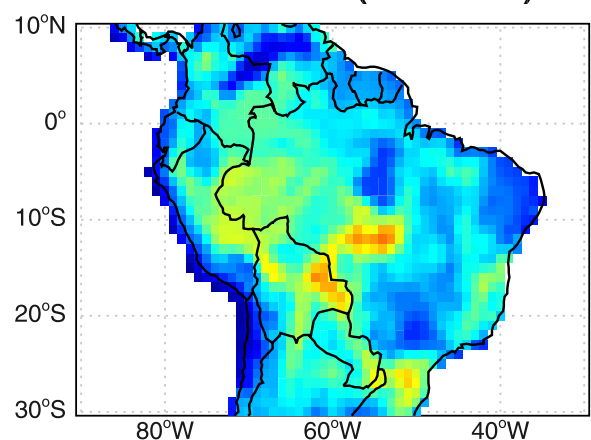

MEGAN (v2006)

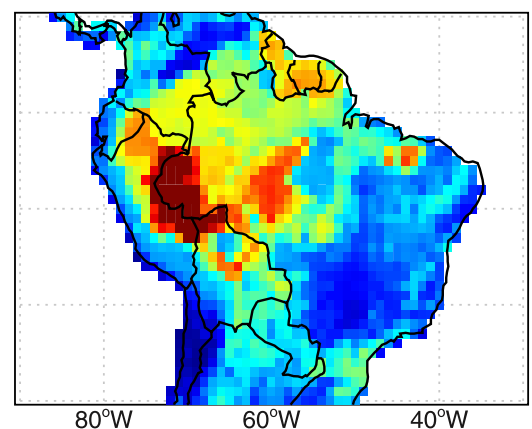

$80^{\circ} \mathrm{W}$

$60^{\circ} \mathrm{W}$

Isoprene emission factors [mg isoprene $\mathrm{m}^{-2} \mathrm{hr}^{-1}$ ]

$\begin{array}{lllllllllllll}0.0 & 1.0 & 2.0 & 3.0 & 4.0 & 5.0 & 6.0 & 7.0 & 8.0 & 9.0 & 10.0 & 11.0 & 12.0\end{array}$

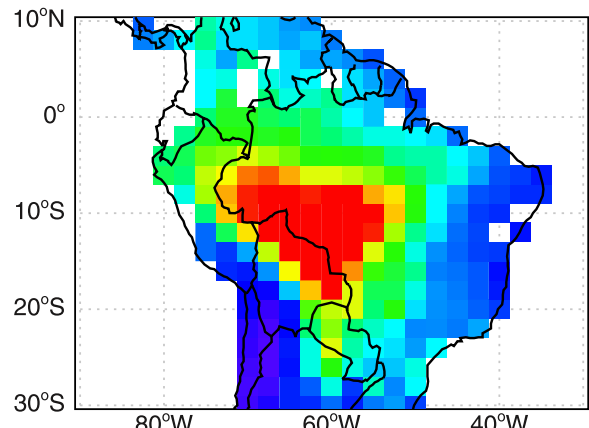

$80^{\circ} \mathrm{W}$

$60^{\circ} \mathrm{W}$

$40^{\circ} \mathrm{W}$

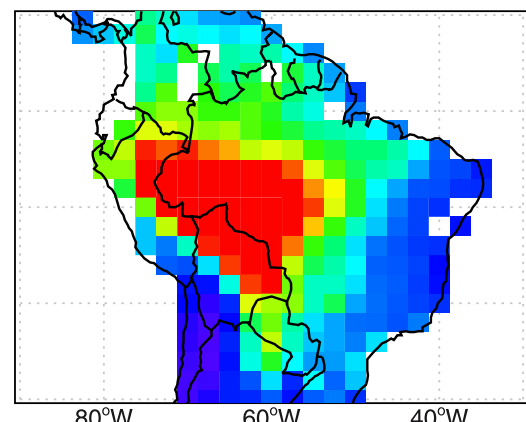

$80^{\circ} \mathrm{W}$

$60^{\circ} \mathrm{W}$

$\mathrm{HCHO}$ vertical columns $\left[\times 10^{16}\right.$ molecules $\left.\mathrm{cm}^{-2}\right]$

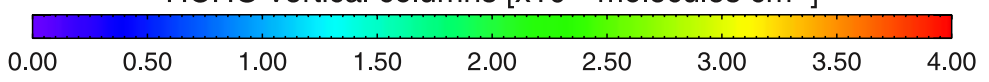

v2006 - v2004

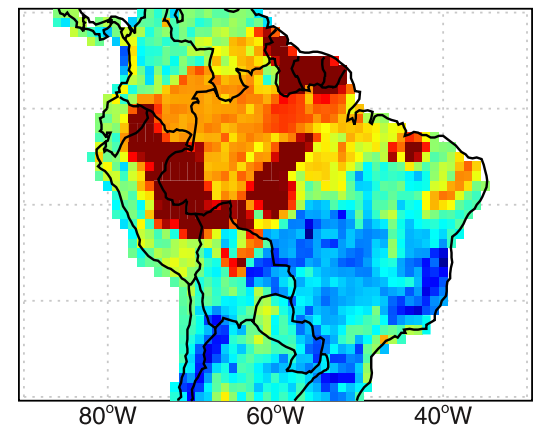

Difference [mg isoprene $\mathrm{m}^{-2} \mathrm{hr}^{-1}$ ]
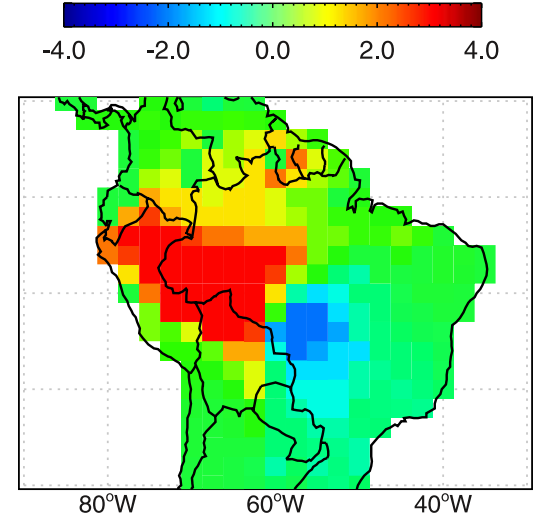

Difference $\left[\times 10^{16}\right.$ molecules $\left.\mathrm{cm}^{-2}\right]$

$\begin{array}{llllll}-1.00 & -0.50 & 0.00 & 0.50 & 1.00\end{array}$

Figure 5. (top) The annual MEGAN isoprene emission factors ( $\mathrm{mg}$ of isoprene $\mathrm{m}^{-2} \mathrm{~h}^{-1}$ ) normalized to standard conditions, on $1^{\circ} \times 1^{\circ}$ grid, downloaded from NCAR in (left) 2004 and (middle) 2006, and (right) their difference (v2006-v2004). (bottom) The corresponding GEOS-Chem HCHO vertical columns (molec $\mathrm{cm}^{-2}$ ) computed for August 2000, sampled at the same time and location of individual GOME observations with cloud cover $\leq 40 \%$, averaged onto the GEOS-Chem $2^{\circ} \times 2.5^{\circ}$ grid. The maximum difference between the HCHO columns is $1.8 \times 10^{16} \mathrm{molec} \mathrm{cm}^{-2}$.

bamboo, palm) in regions such as the Brazil/Peru border [Guenther et al., 2006].

[28] 4. MEGAN v2006 T(1) uses the v2006 emission factors, as described above, but driven with the temperature of the first model layer, $T(1)$.

[29] Figure 5 shows in general v2006 isoprene emission factors are larger than those from v2004, with the exception of Southeast Brazil. The largest differences occur over the Brazil-Peru border, along the east coast over Guyana, Suriname and French Guiana, and over a transect over Brazil which approximately follows the Rio Tapajós and Rio Juruena rivers (reflecting observations made within the Rebio Jaru ecological reserve [see, e.g., Greenberg et al., 2004]).

[30] For each individual data set we sampled the model at the time and location of the data. For computational expediency, we ran the model at a reduced spatial resolution of $4^{\circ} \times 5^{\circ}$. All individual model runs were spun up for at least 2 months from initial conditions, based on previous (6 month) model runs, to let the tracer distributions stabilize.

\subsection{Isoprene: Vertical Profiles and Seasonal Cycle}

[31] Helmig et al. [1998] determined vertical profiles of isoprene and four monoterpenes during 7-15 July 1996 over the Peruvian Amazon, approximately $500 \mathrm{~km}$ west of Iquitos, by collecting air samples onto solid adsorbent cartridge packages that were attached to a balloon and tether line. These experiments resulted in 10 vertical isoprene profiles between the surface $(2 \mathrm{~m})$ and up to $1600 \mathrm{~m}$ height within a primary tropical forest site, of average canopy height $20-30 \mathrm{~m}$. Figure 6 shows a general good agreement between the isoprene in six selected profiles and simulations from the MEGANv2004 T(1) model; the other simulations show a significant positive bias. In contrast to the in situ measurements, which show a rapid decay of isoprene at approximately $1500 \mathrm{~m}$, the models exhibit a much slower decline with altitude as concentrations are well-mixed in the PBL. This disagreement either suggests that (1) isoprene is being consumed above the PBL faster (at this location) than currently simulated or (2) more likely reflects the difference in the PBL heights of the in situ point measurements $(<1500 \mathrm{~m})$ and the relatively coarse model grid square (1500$2000 \mathrm{~m})$.

[32] Kuhn et al. [2007] employed an automated VOC sampler onboard an EMB 1001B1 aircraft, to sample the above-canopy atmosphere over the central Amazon basin 

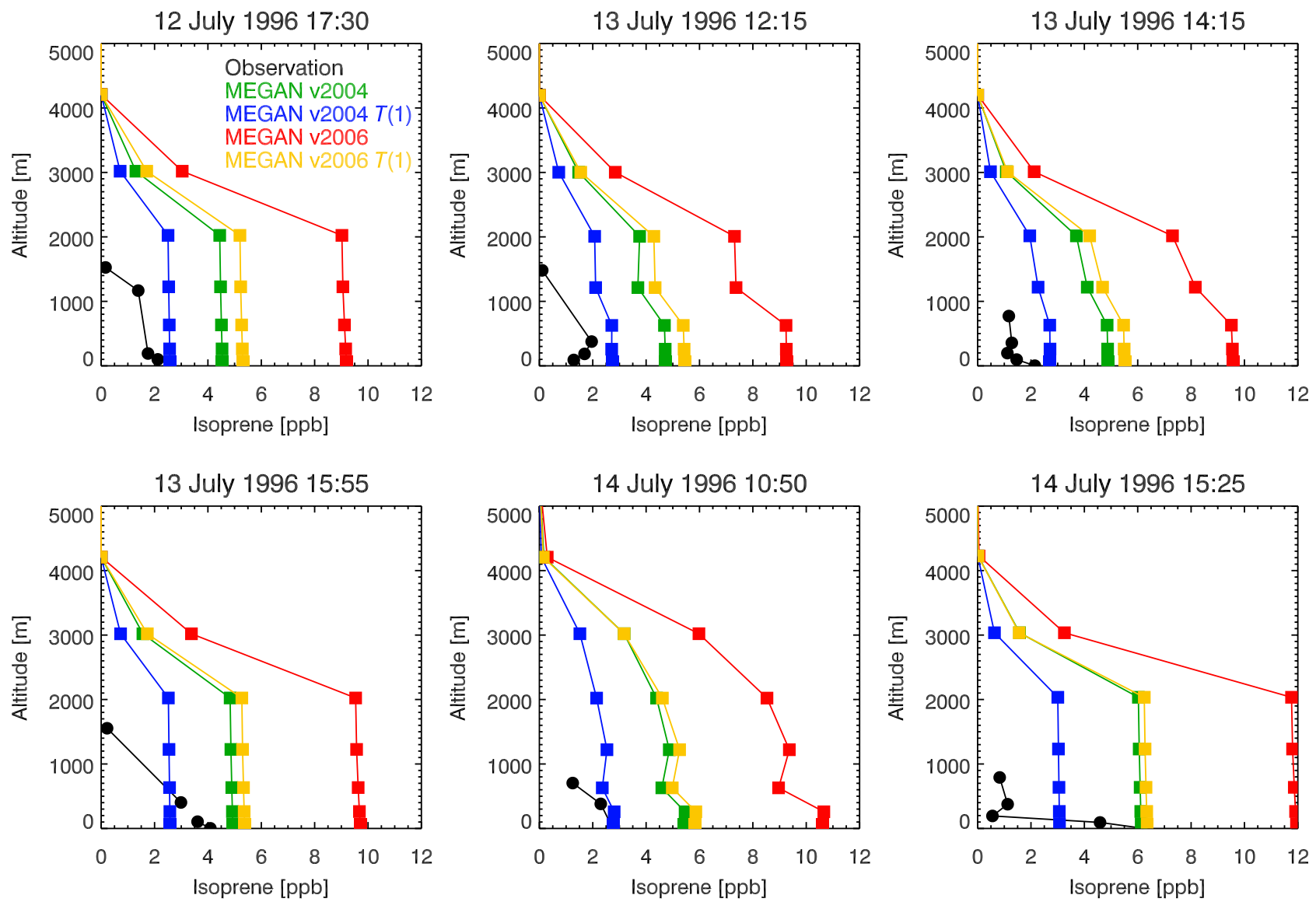

Figure 6. Comparison of model isoprene profiles ( $\mathrm{ppb}$ ) with six of the in situ tethered balloon measurements, observed within the Peruvian Amazon $\left(4.58^{\circ} \mathrm{S}, 77.4^{\circ} \mathrm{W}\right)$ during July $1996[$ Helmig et al., 1998]. Observations are shown in black, alongside the respective MEGAN v2004 (green), MEGAN v2004 T(1) (blue), MEGAN v2006 (red), and MEGAN v2006 T(1) (yellow) model simulations.

during 5-17 July 2001. Figure 7 shows that the observations and the models agree on the confinement of isoprene to the lowermost $1500 \mathrm{~m}$ of the atmosphere, though the observations show a faster decline with altitude near the surface than the model, reflecting errors in model chemistry and transport. The best agreement to the observations is found with MEGANv2004, particularly with the $T(1)$ temperature correction, with average positive model bias of 1-2 ppb. The MEGANv2006 models significantly overestimate the observed isoprene concentrations.

[33] Figure 8 shows the only (almost) complete observed seasonal cycle of isoprene concentrations currently available over the Amazon Basin at Tapajós National Forest, Brazil [Trostdorf et al., 2004]. The observations show a strong seasonal variation with high isoprene concentrations $(3-5 \mathrm{ppbv})$ in both the wet and dry seasons, separated by lower concentrations (1 ppbv) during a wet to dry transitional period (June-July). The measurements also show that isoprene concentrations are typically $30 \%$ higher in the dry season than the wet season, the reason for which is unresolved. Trostdorf et al. [2004] suggest it is linked with water availability but it is also possible that changes in vegetation phenology are responsible [Kesselmeier, 2004; Kuhn et al., 2004a]. Dry season isoprene concentration increases of $100 \%$ have been observed elsewhere in the Amazon [Kesselmeier et al., 2002b]. The models are generally unable to reproduce this pronounced seasonal cycle, with model isoprene concentrations much higher than observations. MEGAN v2004 produces a much closer match to the observations than MEGAN v2006, reproducing the observed variability in the dry season but having a positive bias during the rest of the year. The MEGAN v2004 $T(1)$ simulation fails to capture the dry season isoprene mixing ratios but more accurately estimates the annual mean and has an overall negative bias of $1 \%$, compared with MEGAN v2004 (27\%), MEGAN v2006 (60\%) and MEGAN v2006 $T(1)(41 \%)$ model runs. Model bias is defined here, and elsewhere in the paper, as

$$
\text { bias }=100 \frac{1}{n} \sum_{i=1}^{n} \frac{Q_{i}^{m}-Q_{i}^{o}}{\max \left(Q_{i}^{m}, Q_{i}^{o}\right)},
$$

where $Q_{i}^{m}$ and $Q_{i}^{o}$ are the model and observed quantities respectively [Balkanski et al., 1993]. On the basis of these available observations the MEGAN v2004 T(1) simulation produces the closest match to the observed isoprene mixing ratios over central Amazonia.

\subsection{HCHO: Season Cycle}

[34] Here, we examine model and observed surface $\mathrm{HCHO}$ concentrations at two towers within the Rebio Jaru ecological reserve, located $100 \mathrm{~km}$ north of Ji-Parana in the 

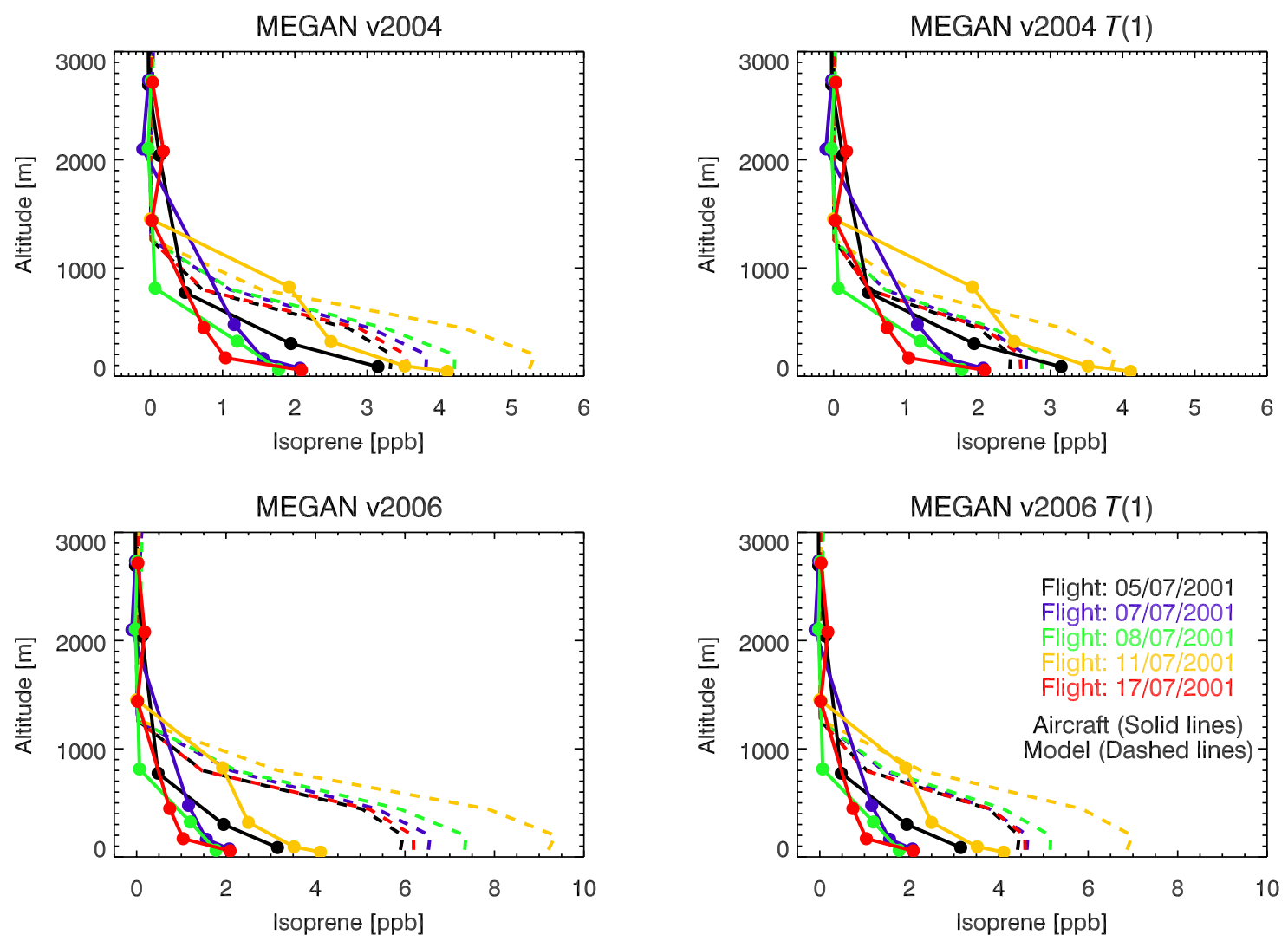

Figure 7. Comparison of model isoprene profiles (ppb) from the four MEGAN simulations (section 4) with aircraft observations over central Amazon (approximately $60 \mathrm{~km} \mathrm{NNW}$ of Manaus, Brazil), during July 2001 [Kuhn et al., 2007]. All aircraft flights took place during the morning (1000-1200 LT), with a typical flight pattern consisting of a continuous spiral upward from $>50 \mathrm{~m}$ to $>3000 \mathrm{~m}$ in altitude, followed by a stepwise spiral descent within the vicinity of the $\mathrm{K} 34$ tower $\left(2.58^{\circ} \mathrm{S}, 60.20^{\circ} \mathrm{W}\right)$ located in the Reserva Biologica do Cuieiras forest reservation.

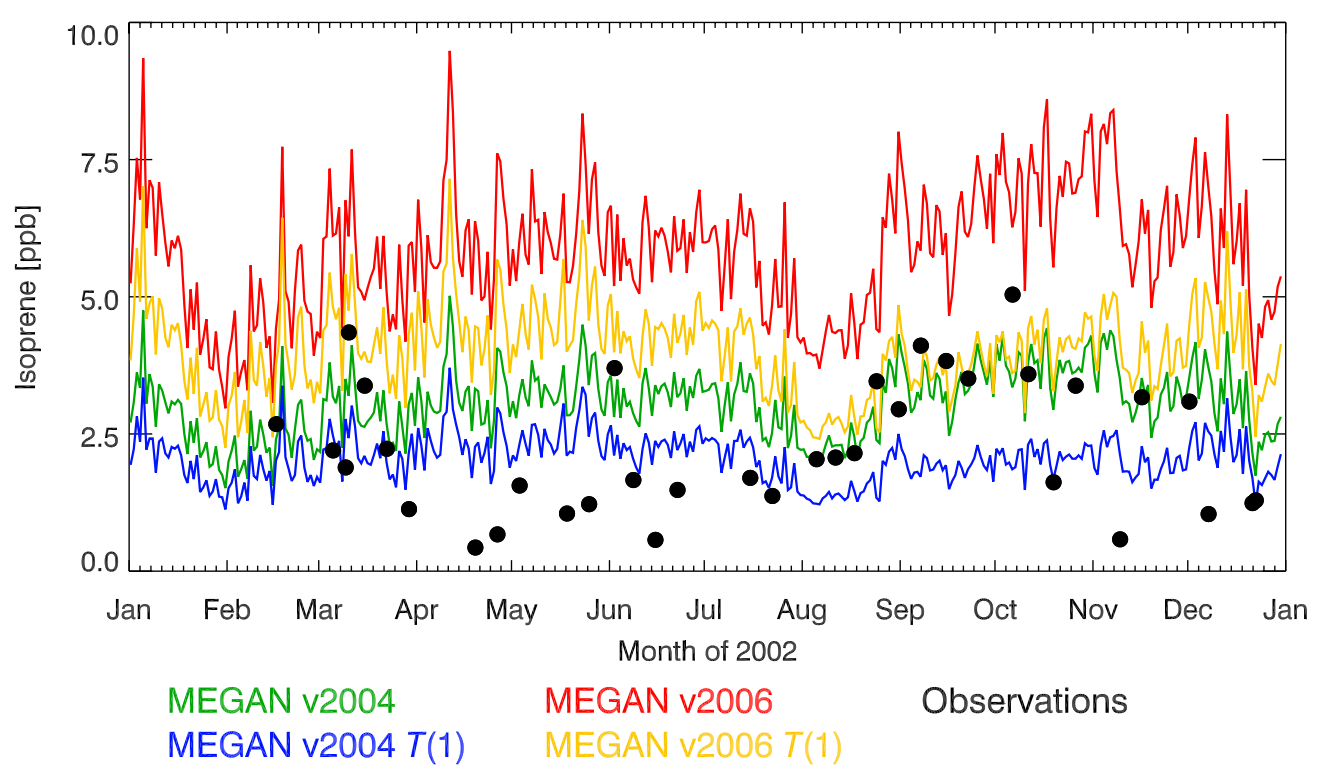

Figure 8. Comparison of model isoprene mixing ratios, corresponding to 1000-1200 LT (sampled daily), with in situ tower measurements (sampling height $\sim 60 \mathrm{~m}$ ) made within the National Forest of Tapajós $\left(3.0^{\circ} \mathrm{S}, 54.9^{\circ} \mathrm{W}\right)$, Brazil, during 2002 [Trostdorf et al., 2004]. The model simulations are: MEGAN v2004 (green), MEGAN v2004 T(1) (blue), MEGAN v2006 (red), and MEGAN v2006 T(1) (yellow) (section 4). 
state of Rondônia, Brazil [Kesselmeier et al., 2002b]. Measurements of $\mathrm{HCHO}$ concentrations were made during the "wet-to-dry" (April-May) and "dry-to-wet" (SeptemberOctober) transition periods of 1999, as part of the LBA-EUSTACH-1 and LBA-EUSTACH-2 campaigns, respectively [Andreae et al., 2002], providing some insight into the seasonal cycle. One tower (hereinafter known as Tower A) was located within the Rebio Jaru nature reserve $\left(10^{\circ} 04^{\prime} 55^{\prime \prime} \mathrm{S}, 61^{\circ} 55^{\prime} 48^{\prime \prime} \mathrm{W}\right)$, and the other tower was located at the Brazilian Environmental Protection Agency Instituto Brasileiro de Meio Ambiente e Recursos Renováveis (IBAMA) camp $\left(10^{\circ} 08^{\prime} 43^{\prime \prime} \mathrm{S}, 61^{\circ} 54^{\prime} 27^{\prime \prime} \mathrm{W}\right)$. Tower A was situated within primary rainforest and the IBAMA tower was located at the edge of secondary forest; canopy heights were $25-45 \mathrm{~m}$ and $8-15 \mathrm{~m}$ respectively. The sampling intake heights for the $\mathrm{HCHO}$ observations used within this work were $52 \mathrm{~m}$ (Tower A) and $\sim 10 \mathrm{~m}$ (IBAMA).

[35] Figure 9 shows that the model and observed concentrations are generally higher by a factor of $2-3$ in the "dry-to-wet" period. The model generally has a positive bias in the "wet-to-dry" months (especially at the IBAMA tower), but shows reasonable agreement during the "dryto-wet" months. MEGAN v2004 T(1) HCHO concentrations are the most consistent with observed values. We find that MEGAN v2004 and MEGAN v2006 T(1) HCHO concentrations are almost indistinguishable. Observed HCHO concentrations show a strong diurnal cycle, with values peaking in late afternoon and decreasing close to zero during night, reflecting the diurnal cycle of isoprene emission and its photochemical destruction, and uptake of $\mathrm{HCHO}$ by vegetation and soils [Jacob and Wofsy, 1988; Kuhn et al., 2002; Rottenberger et al., 2004]. Model HCHO concentrations have a similar diurnal cycle, but HCHO remains relatively high during nighttime. We attribute this to the model nighttime boundary layer falling below the thickness of the first model layer $(\sim 130 \mathrm{~m})$. Above the boundary layer, nighttime isoprene concentrations are assumed to be comparable to daytime values [Rasmussen and Khalil, 1988]. This nighttime excess of isoprene can be converted to $\mathrm{HCHO}$ via reaction with $\mathrm{O}_{3}$ and the nitrate radical $\mathrm{NO}_{3}$. Simulated and observed isoprene mixing ratios at the IBAMA camp (not shown) exhibit the same characteristics of the respective $\mathrm{HCHO}$ data sets.

[36] Figure 10 shows that monthly mean GOME HCHO vertical columns over western South America (defined in Figure 2) peak in the March (wet season) and AugustSeptember (dry season), with very low HCHO columns (close to values determined solely by $\mathrm{CH}_{4}$ oxidation) during a transition period in May. The low HCHO columns observed in May are suggestive of a dramatic reduction in $\mathrm{HCHO}$ production and are consistent with the low $\mathrm{HCHO}$ mixing ratios observed at the IBAMA and tower A sites (Figure 9). Dry season columns are typically $20 \%$ higher than wet season columns. This seasonal cycle is consistent with that of isoprene concentrations shown above in Figure 8. Owing to the fire-screening procedure, the annual and dry season mean HCHO columns over the western zone are $23 \%$ and $66 \%$ lower than the corresponding mean columns over the eastern region, respectively.

[37] Model HCHO columns are generally higher than observed values and do not reproduce the observed seasonal cycle, with columns gradually increasing during May-July reaching a peak in the dry season. Table 3 shows that the annual mean model biases (exclusive of active burning regions) range from 35 to $56 \%$, depending on the model used, with the MEGAN v2004 T(1) simulation providing the best fit to observed columns. The model bias is smaller when both east and west regions are considered together, although the spatial correlation with the GOME HCHO columns is worse. Two possible reasons for the positive model bias include (1) the MEGAN isoprene emissions are too high, and (2) physical processes (e.g., dry deposition, turbulent mixing) and also above and within-canopy chemistry is inadequately represented in the model (section 6). In the latter case, the use of the newer (higher) v2006 emission factors, will amplify this model shortcoming leading to a larger model bias (even if the emission factors are considered to be more accurate). Compared with GEIA [Guenther et al., 1995], the isoprene emissions over the western region predicted by the MEGAN v2004 $T(1)$ and v2006 $T(1)$ simulations are, on average, $30 \%$ and $54 \%$ higher. However, tropical rainforest emissions in GEIA are based on ambient isoprene concentration measurements from only a single study [Zimmerman et al., 1988] and are therefore much more uncertain.

[38] The MEGAN v2004 $T(1)$ model generally provides the closest match to observed concentrations of isoprene and $\mathrm{HCHO}$, and will be used in subsequent model calculations performed at an increased $2^{\circ} \times 2.5^{\circ}$ horizontal resolution. The higher-resolution simulation was initialized by a 6-month spin up from July to December of 1999, and then restarted to run through January to December of 2000. The HCHO shape factors and aerosol fields, used to calculate the GOME AMFs (section 2.1), are taken from this simulation.

\section{Isoprene Emissions Inferred From HCHO Columns}

\subsection{Methodology}

[39] The method adopted to infer VOC emissions from HCHO columns is based on mass balance and follows Palmer et al. [2003]. VOCs emitted into the column at a rate $E_{i}$ (atom $\mathrm{C} \mathrm{cm}^{-2} \mathrm{~s}^{-1}$ ) are oxidized producing HCHO with a per carbon yield $Y_{i}$, with HCHO losses by oxidation and photolysis denoted by the first-order column-integrated loss rate constant $k_{\mathrm{HCHO}}\left(\mathrm{s}^{-1}\right)$. Assuming steady state conditions, and neglecting horizontal transport, the resulting $\mathrm{HCHO}$ column $\Omega$, and its relation to parent VOC emissions, is given by

$$
\Omega=\frac{1}{k_{\mathrm{HCHO}}} \sum_{i} Y_{i} E_{i}
$$

Horizontal transport spatially smears this local relationship by an amount that depends on the wind speed, the rate of production of HCHO from parent VOCs and the lifetime of $\mathrm{HCHO}$. VOCs with large emissions, high $\mathrm{HCHO}$ yields and short lifetimes will generally determine the variability of $\mathrm{HCHO}$ columns, with long-lived VOCs (e.g., $\mathrm{CH}_{4}$ ) largely determining background concentrations. Previous studies over North America in summertime have shown that isoprene, with a lifetime of approximately an hour and a $\mathrm{HCHO}$ yield of $0.3-0.4 \mathrm{C}^{-1}$ depending on $\mathrm{NO}_{\mathrm{x}}$ 
IBAMA: Wet-to-dry transition (Sampling Period: 3-11 May 1999)

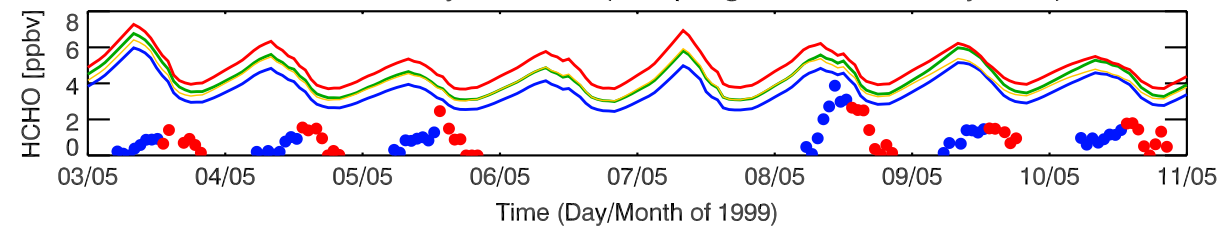

IBAMA: Dry-to-wet transition (Sampling Period: 7-12 October 1999)

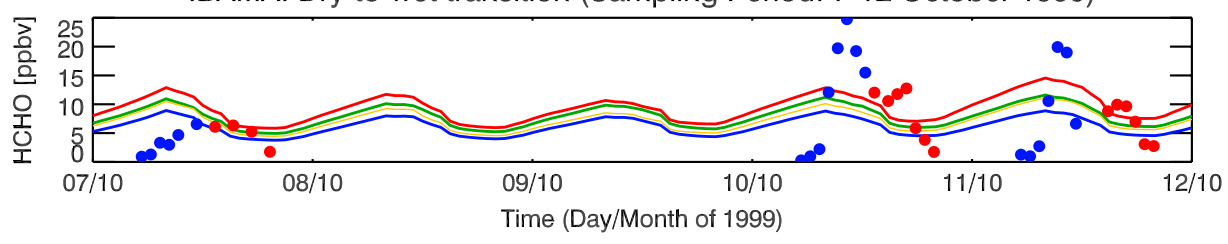

IBAMA: Dry-to-wet transition (Sampling Period: 18-24 October 1999)

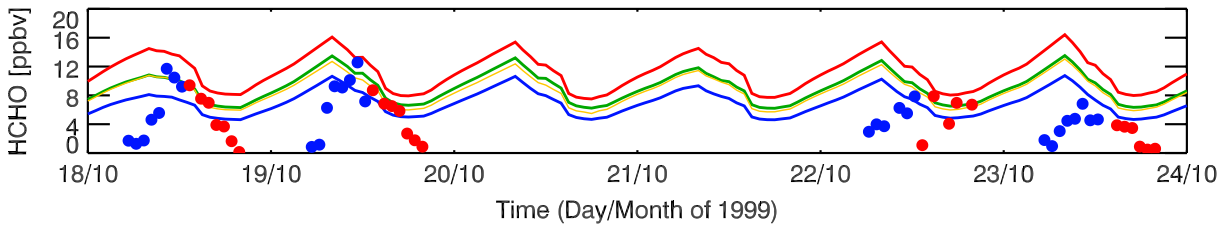

Tower A: Wet-to-dry transition (Sampling Period: 16-18 May 1999)

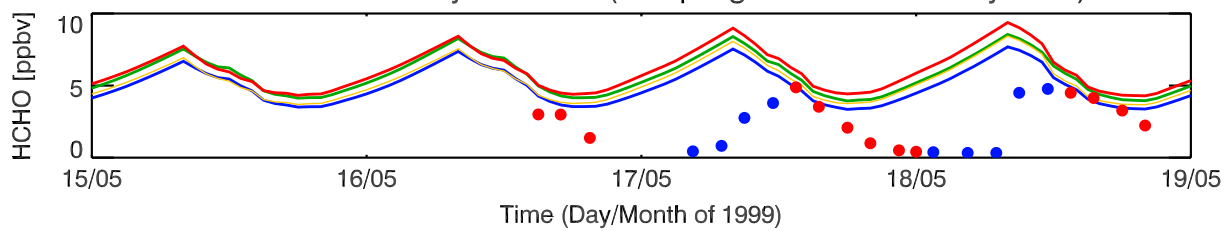

Tower A: Dry-to-wet transition (Sampling Period: 18-25 October 1999)

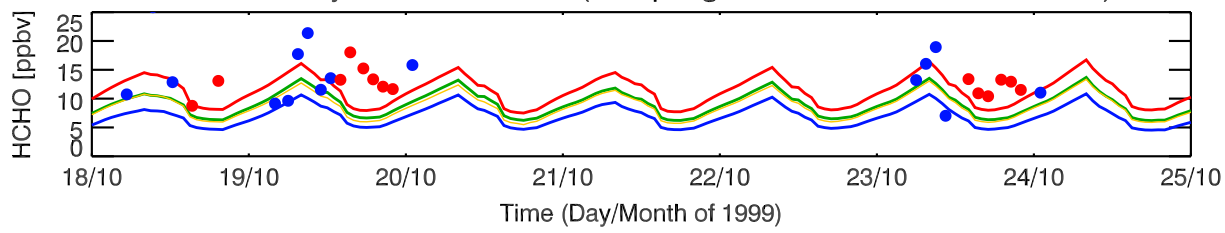

Tower A: Dry-to-wet transition (Sampling Period: 28-31 October 1999)

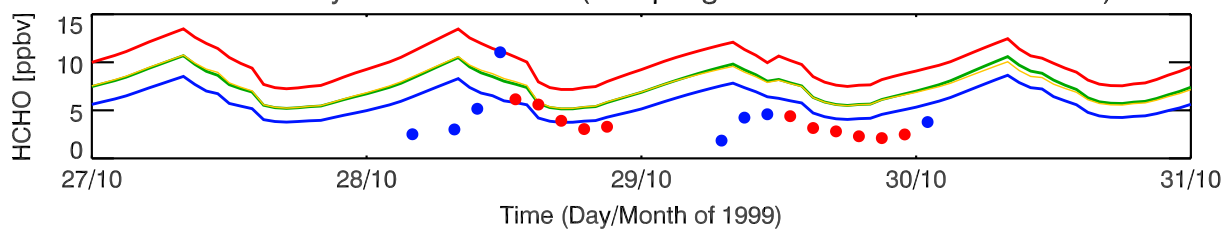

GEOS-Chem (MEGAN v2004) GEOS-Chem (MEGAN v2006)

GEOS-Chem (MEGAN v2004 T(1)) GEOS-Chem (MEGAN v2006 T(1))

Observations: AM:blue dot PM:red dot

Figure 9. Comparison of model $\mathrm{HCHO}$ mixing ratios with in situ tower measurements made within the Rebio Jaru ecological reserve, Rondônia, Brazil, at the IBAMA camp $\left(10^{\circ} 08^{\prime} 43^{\prime \prime} \mathrm{S}, 61^{\circ} 54^{\prime} 27^{\prime \prime} \mathrm{W}\right)$ (top three panels) and at the Tower A site $\left(10^{\circ} 04^{\prime} 55^{\prime \prime} \mathrm{S}, 61^{\circ} 55^{\prime} 48^{\prime \prime} \mathrm{W}\right)$ (bottom three panels), over different sampling periods during 1999 [Kesselmeier et al., 2002b]. Blue and red dots denote morning and afternoon observations, respectively. See section 4.2 for further details.

concentrations, have a spatial smearing length of $<100 \mathrm{~km}$ [Palmer et al., 2003, 2006]. This length scale is comparable with the horizontal dimensions of GOME pixels $\left(40 \times 320 \mathrm{~km}^{2}\right)$, suggesting that observed variability of GOME $\mathrm{HCHO}$ is determined largely by isoprene oxidation [Palmer et al., 2003, 2006; Millet et al., 2006]. Other short-lived biogenic VOCs with similar $\mathrm{HCHO}$ yields, such as $\alpha$ - and $\beta$-pinene, have a delayed production of $\mathrm{HCHO}$ due to the acetone oxidation intermediate, leading to a smearing length of many $100 \mathrm{~s} \mathrm{~km}$.

[40] Over the Amazon, model emissions of monoterpenes and MBO are typically an order and 3 orders of magnitude less than the emissions of isoprene, respectively. Figure 10 shows that isoprene is the primary driver for variability of 


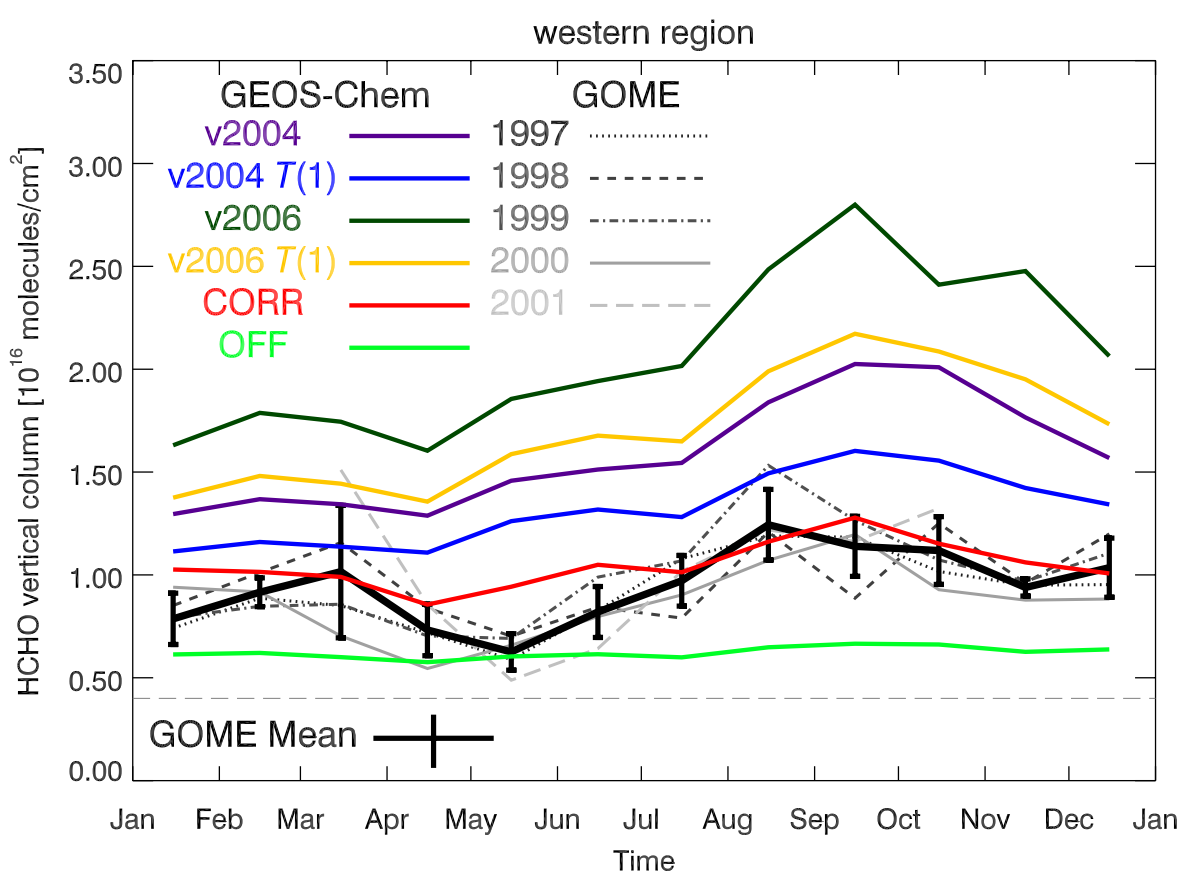

Figure 10. Monthly mean GEOS-Chem and GOME HCHO vertical columns (molec $\mathrm{cm}^{-2}$ ) over western South America (Figure 2) calculated using fire-free regions (section 2.2). The $\pm 1-\sigma$ standard deviation are shown on the GOME mean (black). The v2004, v2004 T(1), v2006, and v2006 T(1) model simulations are shown by the purple, blue, dark green, and yellow lines, respectively. A sensitivity run without any isoprene emissions (OFF) is given by the light green line. The HCHO columns from the $\rho_{c}$ corrected simulation (CORR) (discussed in section 5) are shown in red.

model HCHO columns over tropical South America away from biomass burning, and is supported by our analysis of observed $\mathrm{NO}_{2}, \mathrm{HCHO}$ and firecount data (section 2.2).

[41] To infer isoprene emissions from GOME HCHO observations, we linearly regress model isoprene emissions $E_{\text {MEGAN }}$ (atom $\mathrm{C} \mathrm{cm}^{-2} \mathrm{~s}^{-1}$ ) and HCHO columns $\Omega_{\mathrm{GEOS}}$ (molec $\mathrm{cm}^{-2}$ ) that have been sampled at the time and location of each GOME observation and averaged on the model $2^{\circ} \times 2.5^{\circ}$ grid,

$$
\Omega_{\mathrm{GEOS}}=S E_{\mathrm{MEGAN}}+B .
$$

The slope $S$ (s) represents the HCHO column produced from the emission of isoprene, and the intercept $B$ represents the $\mathrm{HCHO}$ background from the oxidation of longer-lived VOCs. The transfer function used to estimate isoprene emissions that are consistent with observed $\mathrm{HCHO}$ columns can be inferred by transposing equation (4) and using model values of $S$ and $B$,

$$
E_{\mathrm{GOME}}=\frac{\Omega_{\mathrm{GOME}}-B}{S} .
$$

\begin{tabular}{|c|c|c|c|c|c|c|c|c|c|c|}
\hline \multirow[b]{2}{*}{ Month } & \multicolumn{5}{|c|}{$\operatorname{Bias}^{\mathrm{b}}(\%)$} & \multicolumn{5}{|c|}{ Correlation $r^{\mathrm{b}}$} \\
\hline & v2004 & v2004 $T(1)$ & v2006 & v2006 T(1) & CORR & v2004 & v2004 $T(1)$ & v2006 & v2006 T(1) & CORR \\
\hline Jan & $23.1(23.3)$ & $15.1(14.1)$ & $9.6(35.4)$ & $21.8(26.6)$ & $9.3(9.9)$ & $0.36(0.50)$ & $0.38(0.53)$ & $0.27(0.48)$ & $0.30(0.50)$ & $0.48(0.77)$ \\
\hline Feb & $29.7(30.6)$ & $20.5(20.8)$ & $35.1(44.1)$ & $26.6(35.0)$ & 10.9 (11.9) & $0.41(0.76)$ & $0.41(0.75)$ & $0.32(0.75)$ & $.33(0.45)$ & $0.45(0.82)$ \\
\hline Marcl & $48.7(46.8)$ & $43.1(39.6)$ & $53.9(55.6)$ & $48.6(49.5)$ & 37.5 (33.9) & $0.15(0.41)$ & $0.17(0.44)$ & $0.19(0.38)$ & $0.21(0.26)$ & $0.26(0.60)$ \\
\hline April & 59.3 & & 62.0 & 57. & 7.2) & 0.40 & $0.40(0.51)$ & 0.40 & & .61) \\
\hline May & 48.1 & 43.3 & 51.4 & 46.4 & 33.3 & 9) & & 0.24 & & \\
\hline June & $60.3(67.1)$ & $56.5(63.4)$ & $64.3(72.8)$ & $60.8(69.5)$ & $50.0(5$ & 0.43 & $0.43(0.46)$ & $0.41(0.43)$ & $0.42(0.49)$ & $0.49(0.56)$ \\
\hline July & $31.4(34.3)$ & $24.1(26.1)$ & $40.3(46.0)$ & $33.3(38.2)$ & $14.7(15.3)$ & $0.21(0.30)$ & $0.23(0.32)$ & $0.18(0.27)$ & $0.19(0.32)$ & $0.32(0.46)$ \\
\hline & & & & & & & & & & $0.66)$ \\
\hline Sept & & & 46.4 & & & 7) & & 0.5 & & 0.7 \\
\hline Oct & 48.5 & 38.0 & 56.0 & 50.2 & 23.1 & 0.61 & 0 & $0.59(0.55)$ & 7) & $0.77(0.74)$ \\
\hline Nov & $42.2(48.8)$ & 33.9 (40.4) & $49.8(59.6)$ & $42.5(52.4)$ & $20.3(26.8)$ & $0.42(0.56)$ & $0.45(0.59)$ & $0.35(0.51)$ & $0.38(0.56)$ & $0.56(0.72)$ \\
\hline Dec & $44.0(39.6)$ & $37.3(32.5)$ & $52.6(50.9)$ & $46.3(44.1)$ & $22.6(16.6)$ & $0.18(0.42)$ & $0.19(0.42)$ & $0.18(0.42)$ & $0.19(0.24)$ & $0.24(0.54)$ \\
\hline Mean & $42.3(45.1)$ & $34.8(37.2)$ & $49.4(55.5)$ & $42.8(48.5)$ & $24.3(26.7)$ & $0.39(0.50)$ & $0.41(0.52)$ & $0.35(0.47)$ & $0.37(0.49)$ & $0.49(0.65)$ \\
\hline
\end{tabular}

Table 3. Comparison of GEOS-Chem and GOME HCHO Vertical Columns for 2000 Over Tropical South America ${ }^{\mathrm{a}}$

${ }^{\mathrm{a}}$ Tropical South America is defined as the western and eastern regions shown in Figure 2.

${ }^{b}$ Model biases (equation (7)) and correlations are for the MEGAN v2004, MEGAN v2004 T(1), MEGAN v2006, and $\rho_{c}$ corrected (CORR) simulations respectively (sections 4 and 5.2), relative to the HCHO vertical columns observed by GOME (calculated using AMFs from the corresponding model run). Values in parentheses are for the western region alone. 

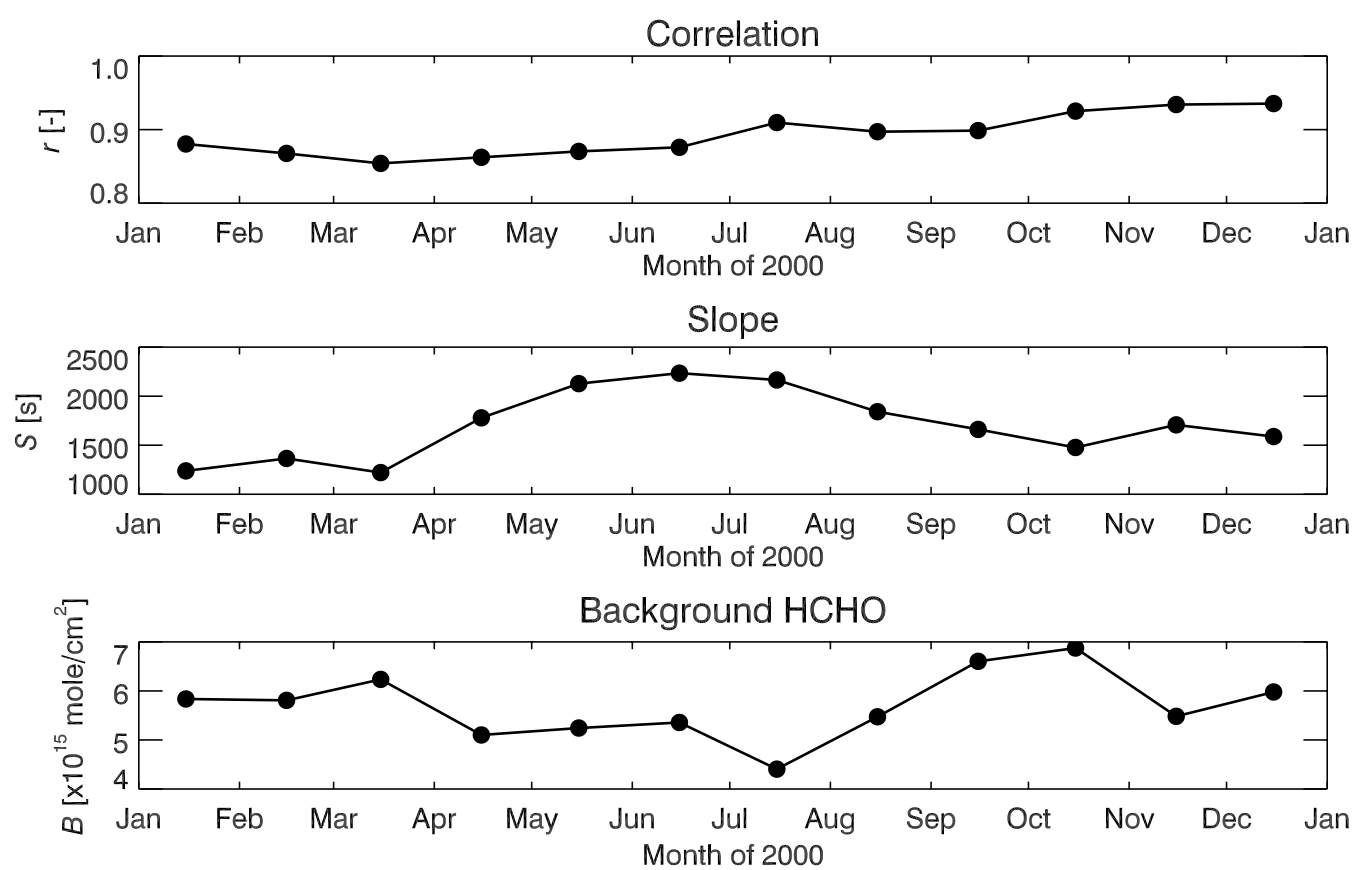

Figure 11. (top) Monthly mean correlations and (middle and bottom) linear regression coefficients (equation (4)) between the model isoprene and HCHO columns over western South America (Figure 2) during 2000. Model data are sampled along GOME's orbital track at the same time and location of individual observations with cloud cover $\leq 40 \%$, and averaged on to the $2^{\circ} \times 2.5^{\circ}$ GEOS-Chem grid.

Previous studies have either defined regional transfer functions on the basis of prior knowledge of vegetation and spatial patterns of observed GOME HCHO columns [Palmer et al., 2003, 2006], or spatially resolved transfer functions to take advantage of better spatial resolved data from the Ozone Monitoring Instrument (OMI) [Millet et al., 2007]. For this study we use a transfer function representative of the whole western domain (Figure 2) owing to the GOME data that are not contaminated by clouds or fires.

[42] Figure 11 shows the correlations between the isoprene emissions and $\mathrm{HCHO}$ columns calculated by GEOS-Chem over tropical South America for the year 2000, and the associated monthly mean regression slopes and backgrounds. The high correlations, generally $>0.85$, reflect the strong local dependence of $\mathrm{HCHO}$ columns over this region on isoprene emissions, also demonstrated by Figure 10. Model slopes show a clear seasonal variation, with lowest values in the wet season (January-March) and highest values in the transitional and dry seasons (AprilSeptember). This variation reflects higher average $\mathrm{OH}$ model concentrations $\left(2.1-2.2 \times 10^{6}\right.$ molec cm $\left.{ }^{-3}\right)$ in the wetter months (owing to an abundance of water vapor), and lower $\mathrm{OH}$ concentrations $\left(1.3-1.8 \times 10^{6}\right.$ molec $\left.\mathrm{cm}^{-3}\right)$ in the transitional period. $\mathrm{OH}$ availability affects the regression slopes $\left(\sim Y_{\text {Isoprene }} / k_{\mathrm{HCHO}}\right)$ as it influences the rate and amount of $\mathrm{HCHO}$ generated, and the rate at which $\mathrm{HCHO}$ is lost.

[43] Background values range from 4.4 to $6.9 \times$ $10^{15}$ molec $\mathrm{cm}^{-2}$, with smallest values during the wetto-dry transition period. This variation likely represents an integrated background from the oxidation of VOCs with lifetimes too long for GOME to distinguish them individually [Palmer et al., 2006]. We use these monthly linear transfer functions from 2000 to infer isoprene emissions for the whole GOME record considered in this paper, $1997-$ 2001. We chose 2000 because it directly corresponds to the time period of the AVHRR LAI data. Previous studies have shown that interannual variability in the transfer functions is small [Palmer et al., 2006].

\subsection{Seasonal and Interannual Variability of GOME Isoprene Emissions}

[44] Figure 12 shows the seasonal variation in GOME and MEGAN isoprene emissions during May-November 2000. There is broad agreement between MEGAN and GOME temporal variations in isoprene but the spatial agreement is generally poor, with spatial correlations

Figure 12. Monthly mean isoprene emissions (atom $\mathrm{C} \mathrm{cm}^{-2} \mathrm{~s}^{-1}$ ) during May-November 2000, corresponding to 10001200 LT, over: (a) the western region (excluding fire-contaminated regions), as derived by GOME; (b) the western region, as predicted by MEGAN at the GOME locations (MEGAN $(G)$ ); (c) the entire Amazon, using GOME emissions integrated with $\rho_{c}$ corrected MEGAN emissions (GOME (I)); and (d) the entire Amazon, predicted by the (uncorrected) MEGAN emissions. The solid black line represents the division between the east and west regions defined in Figure 2 . The emissions are averaged on to the $2^{\circ} \times 2.5^{\circ}$ GEOS-Chem grid and correspond to observations where the cloud cover is $\leq 40 \%$. The monthly totals are shown inset. (e) The MODIS EVI monthly distributions which are an indicator of vegetation greening (section 5.2), remapped on to the GEOS-Chem grid [Huete et al., 2002]. 
typically $<0.4$. Spatial correlations between MEGAN and GOME, during August and September when emissions peak, are much higher with values of 0.7 and 0.6 , respectively. GOME and MEGAN agree on higher isoprene emissions during the dry season, determined in MEGAN by the higher temperatures and light levels [Guenther et al., 1995]. MEGAN predicts much greater emissions than GOME, over west Brazil during August-October. MEGAN generally has a positive bias, with the bias larger in the dry season than the wet season (Table 4).

\section{A: GOME B: MEGAN (G) C: GOME (I) D: MEGAN E: EVI}
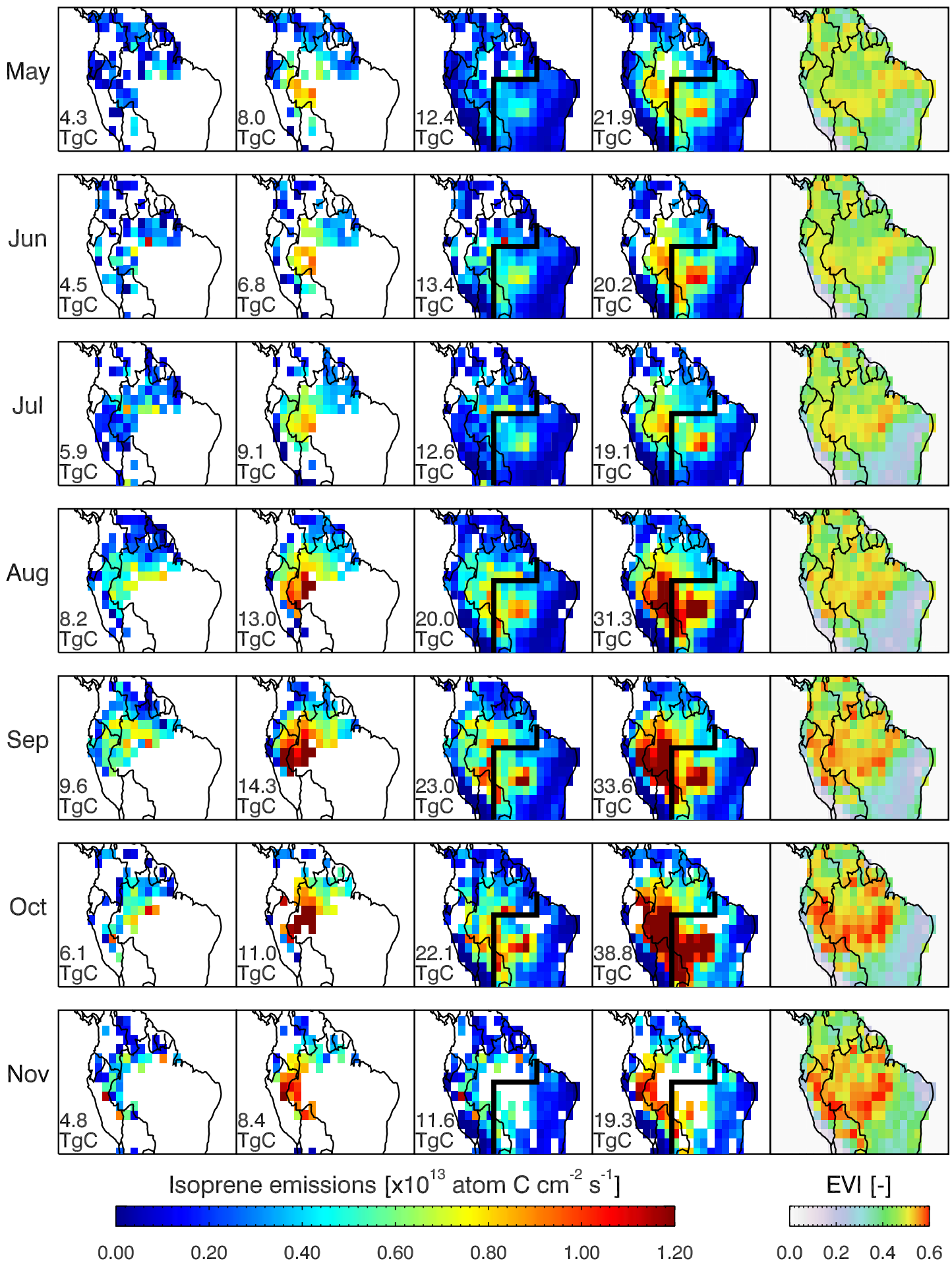

Figure 12 
Table 4. Summary of the GOME and MEGAN Isoprene Emissions for the Year 2000 Over Tropical South America ${ }^{\text {a }}$

\begin{tabular}{|c|c|c|c|c|c|c|c|c|c|c|c|c|}
\hline \multirow{3}{*}{$\frac{\text { Month }}{\text { Jan }}$} & \multicolumn{4}{|c|}{ Monthly Totals (Tg C) } & & & & & \multicolumn{4}{|c|}{ EVI Correlation ${ }^{\mathrm{b}}$} \\
\hline & \multicolumn{2}{|c|}{$\mathrm{GOME}^{\mathrm{c}}$} & \multicolumn{2}{|c|}{ MEGAN $^{\mathrm{d}}$} & \multicolumn{2}{|c|}{ Bias $(\%)$} & \multicolumn{2}{|c|}{ Correlation } & \multicolumn{2}{|c|}{$\mathrm{GOME}^{\mathrm{c}}$} & \multicolumn{2}{|c|}{ MEGAN $^{\mathrm{d}}$} \\
\hline & 19.2 & (7.9) & 24.9 & (9.9) & 19.3 & $(9.2)$ & 0.71 & $(0.31)$ & - & - & - & - \\
\hline Feb & 13.1 & (3.0) & 18.0 & $(4.2)$ & 25.8 & $(21.4)$ & 0.88 & $(0.60)$ & 0.58 & $(0.45)$ & 0.62 & $(0.57)$ \\
\hline March & 11.4 & $(4.0)$ & 15.7 & (4.7) & 27.5 & $(9.3)$ & 0.70 & $(0.29)$ & 0.46 & $(0.30)$ & 0.60 & $(0.73)$ \\
\hline April & 8.2 & $(2.5)$ & 16.2 & (4.5) & 47.2 & (31.6) & 0.82 & $(0.46)$ & 0.46 & $(0.24)$ & 0.58 & $(0.57)$ \\
\hline May & 12.4 & (4.3) & 21.9 & $(8.0)$ & 37.8 & $(30.2)$ & 0.72 & $(0.14)$ & 0.43 & $(0.20)$ & 0.53 & $(0.43)$ \\
\hline June & 13.4 & $(4.5)$ & 20.2 & (6.8) & 29.6 & (19.8) & 0.81 & $(0.33)$ & 0.49 & $(0.11)$ & 0.55 & $(0.38)$ \\
\hline July & 12.6 & (5.9) & 19.1 & $(9.1)$ & 28.4 & (20.9) & 0.72 & $(0.27)$ & 0.45 & $(0.12)$ & 0.68 & $(0.70)$ \\
\hline Aug & 20.0 & $(8.2)$ & 31.3 & $(13.0)$ & 33.5 & $(30.3)$ & 0.93 & $(0.70)$ & 0.54 & $(0.36)$ & 0.58 & $(0.50)$ \\
\hline Sept & 23.0 & (9.6) & 33.6 & $(14.3)$ & 27.8 & $(23.5)$ & 0.90 & $(0.60)$ & 0.58 & $(0.24)$ & 0.63 & $(0.61)$ \\
\hline Oct & 22.1 & (6.1) & 38.8 & $(11.0)$ & 41.0 & (37.3) & 0.91 & $(0.49)$ & 0.55 & $(0.14)$ & 0.60 & $(0.48)$ \\
\hline Nov & 11.6 & $(4.8)$ & 19.3 & (8.4) & 36.1 & $(32.5)$ & 0.78 & $(0.47)$ & 0.59 & $(0.30)$ & 0.74 & $(0.71)$ \\
\hline Dec & 14.3 & (3.6) & 25.2 & $(6.2)$ & 42.5 & $(36.2)$ & 0.80 & $(0.23)$ & 0.50 & $(-0.02)$ & 0.66 & $(0.69)$ \\
\hline Mean & 15.1 & (5.4) & 23.7 & (8.3) & 33.0 & $(25.2)$ & 0.81 & $(0.41)$ & 0.47 & $(0.20)$ & 0.56 & $(0.53)$ \\
\hline
\end{tabular}

${ }^{a}$ Tropical South America is defined as the western and eastern regions shown in Figure 2. Values in parentheses correspond to data over the western region alone (exclusive of fire-contaminated regions).

${ }^{\mathrm{b}}$ The correlation of the GOME and MEGAN isoprene emissions with the MODIS Enhanced Vegetation Index (EVI) (section 5.2).

${ }^{\mathrm{c}}$ The GOME emissions are integrated with the $\rho_{c}$ corrected MEGAN values (section 5.2). Data over the western region correspond to top-down GOME emissions only.

${ }^{\mathrm{d}}$ MEGAN emissions are taken from the v2004 $T(1)$ simulation (section 4.2).

[45] To develop a contiguous distribution of isoprene emissions over tropical South America for subsequent model calculations we combine MEGAN and GOME isoprene emissions, filling in undetermined grid squares (excluded because of biomass burning) using the model emissions. We take into account that MEGAN estimates isoprene emitted from the canopy foliage, whereas GOME infers the net isoprene flux emitted from above the forest canopy, i.e., including above and within-canopy chemistry and physics, by approximating a canopy production and loss ratio, relative to the model, $\rho_{c}$,

$$
\rho \approx \rho_{c}=\frac{E_{\mathrm{GOME}}-E_{\mathrm{MEGAN}}}{E_{\mathrm{MEGAN}}},
$$

where $E_{\mathrm{GOME}}$ and $E_{\mathrm{MEGAN}}$ are the observed and model isoprene emissions at each model grid square, respectively. The ratio $\rho_{c}$ reflects not only losses within the canopy but also possible inadequately parameterized or poorly constrained GEOS-Chem model processes (e.g., turbulent mixing, missing chemical sinks) within the PBL.

[46] For each individual cloud-free GOME observation we calculate a "corrected" MEGAN isoprene emissions using $\left(E_{\text {MEGAN }}\right)_{c}=E_{\text {MEGAN }}+\left(E_{\text {MEGAN }} \times \rho_{c}\right)$. Values of $\rho_{c}$ range -0.99 to 0.95 . Monthly mean correction factors were applied to model grid points where $\rho_{c}$ was unable to be calculated, and additionally to those grid boxes falling in the eastern region (where burning is widespread and $\rho_{c}$ is considered only as a first approximation). Monthly mean $\rho_{c}$ values range from -0.25 to -0.44 ; the average monthly correction is -0.36 . The correction factors are significantly greater than current in-canopy loss estimates $(\sim 10 \%)$ [Guenther et al., 2006; Kuhn et al., 2007; Karl et al., 2007].

[47] Figure 12 shows the contiguous isoprene distribution determined by GOME and MEGAN for 2000. Note that using monthly mean $\rho_{c}$ to scale MEGAN isoprene emissions over the eastern region does not alter the spatial distribution of emissions, reflected by spatial correlations given in Table 4. We find that MEGAN isoprene emissions are $33 \%$ higher than the emissions inferred from GOME (Table 4). During the dry season, the highest isoprene emitting areas are over central and western Amazon and along the Brazilian borders with Peru and Bolivia. Figure 12 also shows that variations in MEGAN and GOME isoprene emissions are consistent with variations in the Enhanced Vegetation Index (EVI), an indicator of vegetation greening, determined from the MODIS sensor [Justice et al., 1998; Huete et al., 2002]. The average spatial correlation during the dry season, between the EVI and the GOME and MEGAN isoprene emissions are 0.57 and 0.64 respectively (over the combined eastern and western regions; see Table 4). Recent studies have documented an average $25 \%$ increase in EVI over the Amazon basin during the dry season when temperatures and level of sunlight are generally higher than the rest of the year [Huete et al., 2006; Saleska et al., 2007], suggesting that sunlight has more influence on mature rainforest productivity than previously thought. Deep rooting of mature plant species ensures access to soil water throughout the year [Nepstad et al., 1994; da Rocha et al., 2004], so unless vegetation experience severe drought stress isoprene emissions are unlikely to be significantly affected [Pegoraro et al., 2006].

[48] Figure 13 shows the contiguous GOME/MEGAN isoprene emissions over 1997-2001. There is little year-toyear variation in the seasonal distribution of emissions over this period, with emissions generally increasing from May and peaking in August and September, consistent with the seasonal variation in HCHO columns (Figure 1, section 2.2). The Amazon Basin (western Brazil) consistently has the largest emissions, with emissions over the Guyannas, Peru and the northwestern countries generally lower. The highest annual isoprene emissions occur in El Niño years (1997/ 1998), owing to the associated warmer temperatures, in agreement with previous studies [e.g., Lathière et al., 2006; Müller et al., 2008].

[49] Figure 14 shows that including GOME isoprene emissions in GEOS-CHEM improves the agreement between model and observed $\mathrm{HCHO}$ column, with the mean model bias reduced from $35 \%$ to $24 \%$ and the spatial correlation increased slightly from 0.41 to 0.46 (Table 3 ). If we consider only the less noisy observed columns over the western region, the GOME isoprene emissions reduce the mean model bias from $36 \%$ to $25 \%$ and increase the spatial 

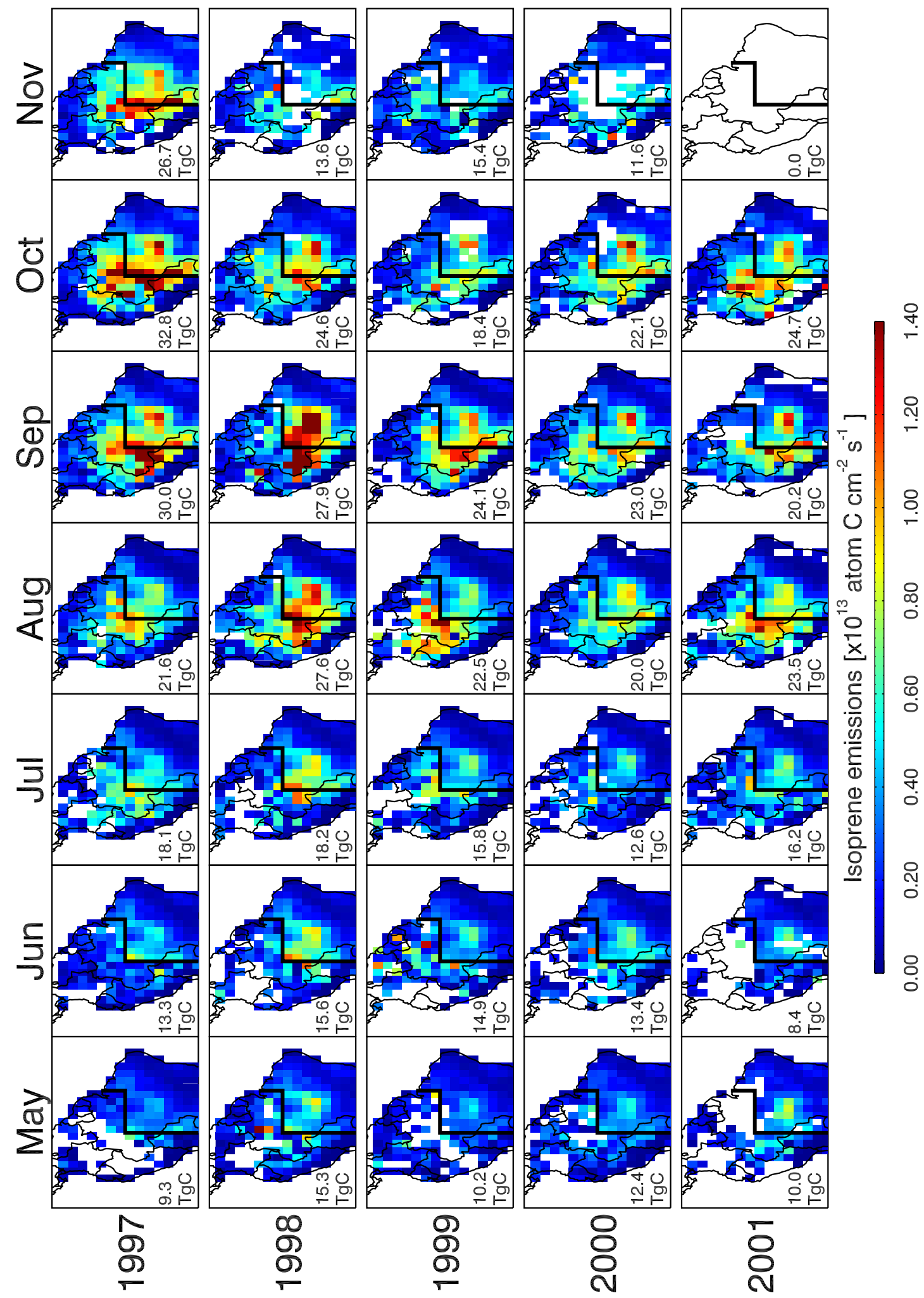

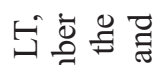

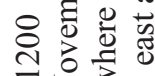

7 乙

定空. 总

$\circ$ op $\sum_{0} \sum_{0}^{3}$

.

ำ

运.

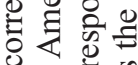

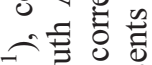

的践

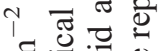

ํํ응

$\cup \Xi$

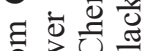

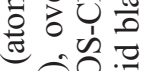

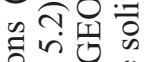

号 in

8 हี

\& $\times$.

ขีำ

ํㅡㅇ.월

. ڤ.

गู ฮี

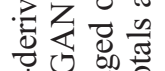

嵌需

$\sum_{0} \sum_{0}^{2}$

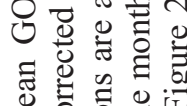

8. छ

궁.

莒

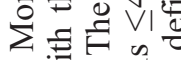

ले

๘

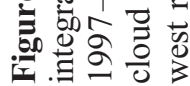



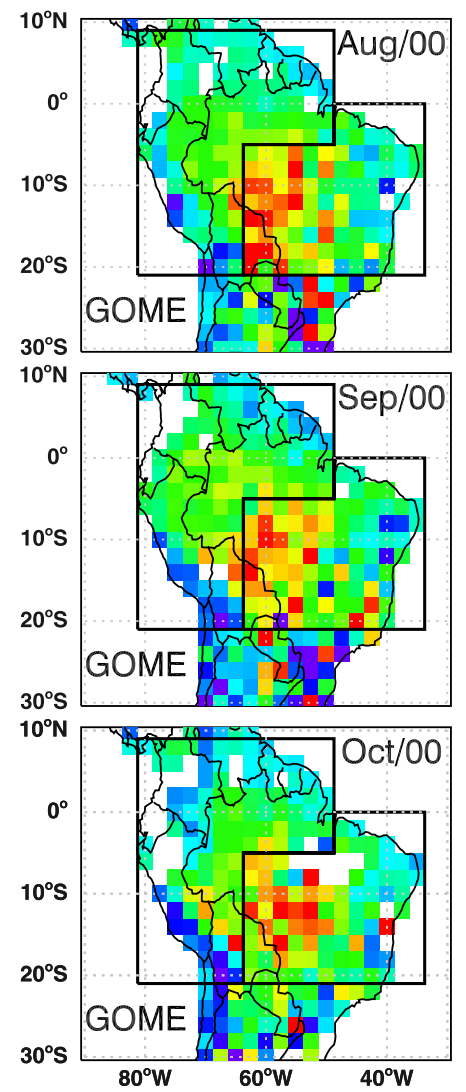

$\mathrm{HCHO}$
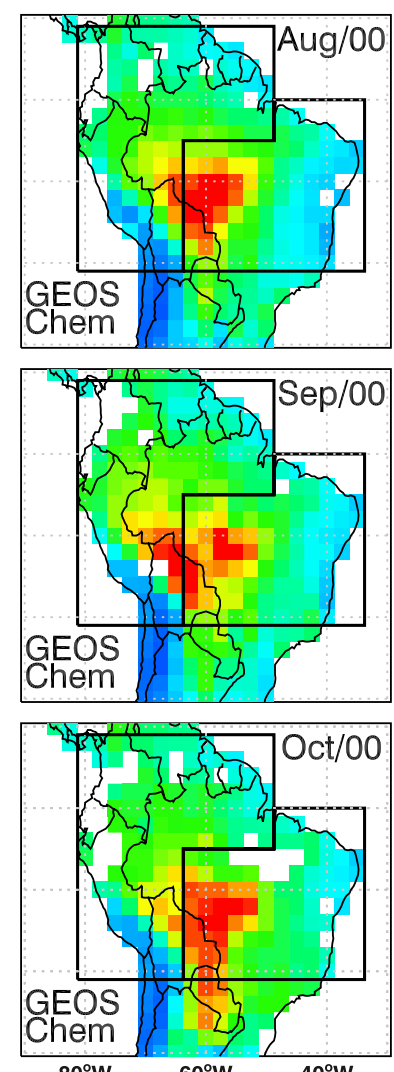

$80^{\circ} \mathrm{W} \quad 60^{\circ} \mathrm{W} \quad 40^{\circ} \mathrm{W}$
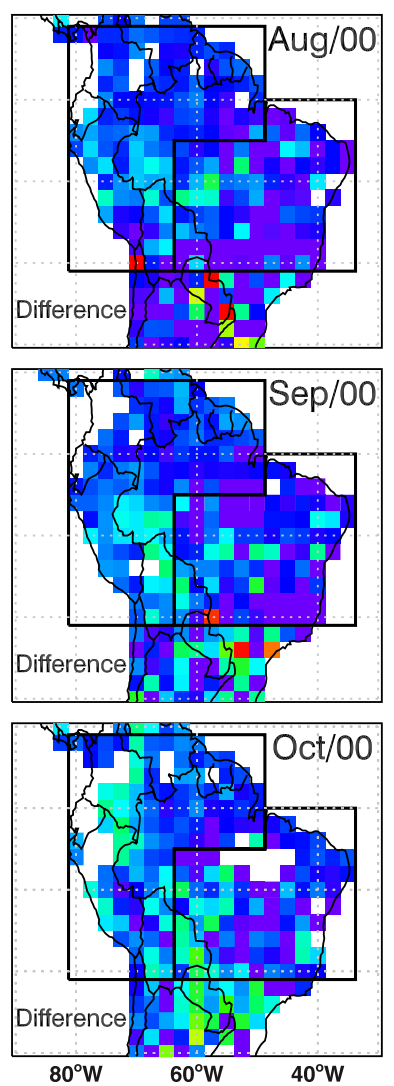

$80^{\circ} \mathrm{W}$

$\left.\mathrm{m}^{-2}\right]$

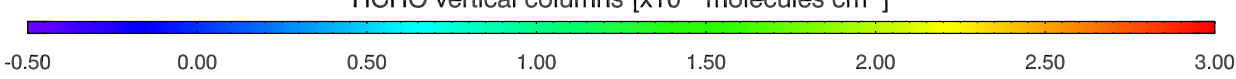

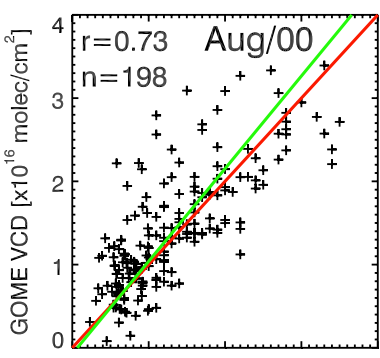
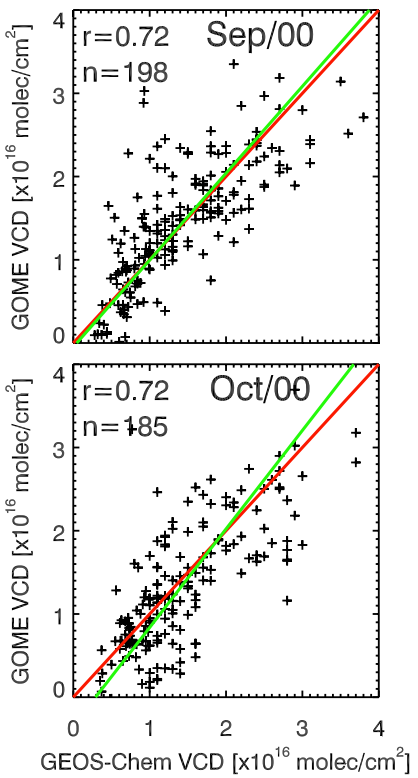

GEOS-Chem VCD $\left[\times 10^{16} \mathrm{molec} / \mathrm{cm}^{2}\right]$

Figure 14. GOME and GEOS-Chem HCHO vertical columns for July-September 2000. The model columns have been computed using GOME isoprene emissions integrated with MEGAN corrected using the factor $\rho_{c}$ (section 5.2). Their difference (GEOS-Chem - GOME) is also shown. The data have not been screened for biomass burning (section 2.2). Scatterplots of GOME versus model HCHO columns are shown at the right. The red line indicates the $x=y$ relation and the green line the reduced major axis regression [Hirsch and Gilroy, 1984]. The regression equations for August, September and October are: $y=1.11 x-7.39 \times 10^{14}, y=1.04 x-4.75 \times 10^{14}$, and $y=1.18 x-3.45 \times 10^{15}$. The correlation coefficient $r$ and the number of useable grid squares $n$ are also shown.

correlation from 0.53 to 0.64 . The temporal variability of the $\rho_{c}$-corrected columns is more consistent (than the uncorrected columns) with the observed columns for all years studied, particularly during the dry season (Figure 10). It is clear therefore, that implementing an above and within-canopy production and loss factor is a requirement for modeling the net isoprene fluxes over the tropical Amazon (within the GEOS-Chem framework).

\subsection{Error Analysis}

[50] We estimate the total error, $\varepsilon$, of the emissions inferred from GOME HCHO columns as the quadrature sum of (1) the slant column fitting error $\varepsilon_{F}$, (2) the error in the AMF calculation $\varepsilon_{A}$, (3) the error of diffuser plate correction $\varepsilon_{D}$, and (4) the errors corresponding to the gradient $\varepsilon_{S}$ and intercept $\varepsilon_{B}$ of the linear transfer function (equation (4)),

$$
\varepsilon=\sqrt{\left(\frac{\varepsilon_{F}}{\Omega}\right)^{2}+\left(\varepsilon_{A} \times A M F\right)^{2}+\left(\varepsilon_{D}\right)^{2}+\left(\varepsilon_{S}\right)^{2}+\left(\varepsilon_{B}\right)^{2}} .
$$

The first three terms are related to the retrieval of the $\mathrm{HCHO}$ vertical column. We normalize the slant column spectral fitting error $\left(4 \times 10^{15} \mathrm{molec} \mathrm{cm}^{-2}\right)$, and the AMF calculation error $(30 \%)$, by the slant column density and the AMF, respectively, and assign a uniform value of $10 \%$ (i.e., $\sim 1.0 \times$ $10^{14}$ molec $\mathrm{cm}^{-2}$ ) to the uncertainty in the diffuser plate correction, consistent with the work of Shim et al. [2005] and Palmer et al. [2006]. We find the average sum of these terms to be $76 \%$, and $91 \%$ over the western and eastern regions, respectively. Degradation of the HCHO retrieval by the SAA contributes to the higher values in the eastern zone.

[51] The last two terms $\varepsilon_{S}$ and intercept $\varepsilon_{B}$ represent the errors in the GEOS-Chem chemistry mechanism. Previous studies focused on North America have assigned an error of $30 \%$ to the linear regression based on comparisons to in situ observations and to the Master Chemical Mechanism [Palmer et al., 2006; Millet et al., 2006]. Over the Amazon in low- $\mathrm{NO}_{\mathrm{x}}$ conditions, the fate of $\mathrm{RO}_{2}$ radicals produced from isoprene oxidation by $\mathrm{OH}$ and the subsequent recycling of organic peroxides is much more uncertain 
[Palmer et al., 2003, 2006]. We therefore assign a higher estimate of $60 \%$ to the error in the regression gradient $\varepsilon_{S}$ to reflect the incomplete knowledge of the more complex oxidation pathways, acknowledging that this estimate may be conservative. We allocate an error of $15 \%$ to represent the uncertainty in the $\mathrm{HCHO}$ background, $\varepsilon_{B}$, from the oxidation of $\mathrm{CH}_{4}$ and other unparameterized or unknown VOCs.

[52] Using these assigned values we calculate a total error in the GOME isoprene emissions, derived over the western region, of about $98 \%$. Errors associated with isoprene emissions inferred from GOME data over the eastern region, where we have used the average $\rho_{c}$ values (derived from the western region), are much higher (>100\%). Despite these top-down isoprene emissions being uncertain by at least a factor of 2 they are still comparable with current bottom-up inventories whose emission estimates can vary by at least a factor of 2 to 3 depending on the driving variable data employed [Guenther et al., 2006].

\subsection{What Controls Variations in Isoprene Emissions Over the Amazon?}

[53] Variations in isoprene emissions are predominately driven by fluctuations in temperature. Within MEGAN, the temperature variability is parameterized by the activity factor $\gamma_{T}$ (equation (1)), which is defined as

$$
\gamma_{T}=\frac{E_{o p t} \cdot C_{T_{2}} \cdot \exp \left(C_{T_{1}} x\right)}{C_{T_{2}}-C_{T_{1}}\left(1-\exp \left(C_{T_{2}} x\right)\right)},
$$

where $x=\left(1 / T_{\text {opt }}-1 / T\right) / R$ with $T$ the leaf temperature $(\mathrm{K}), R$ is the gas constant, $E_{\text {opt }}$ is the maximum value for $\gamma_{T}$, and $T_{\text {opt }}$ is the temperature at which $\gamma_{T}=E_{\text {opt }}$. Both $C_{T_{1}}=76 \ell^{-1}$ $\mathrm{MPa}^{-1}$ mol and $C_{T_{2}}=160 \ell^{-1} \mathrm{MPa}^{-1}$ mol are empirical coefficients representing the activation and deactivation energies of isoprene emissions, respectively [Guenther et al., $1999,2006]$. The functional form of equation (8) exponentially increases isoprene emissions with increasing leaf temperatures up to a maximum $T_{o p t}$, above which there is a rapid fall-off reflecting a breakdown in leaf biochemistry [Singsaas and Sharkey, 2000]. $T_{\text {opt }}$ and $E_{\text {opt }}$ are also a function of the mean 24-hour average temperature $(\mathrm{K})$ over the past 15 days, $T_{15}$ [Guenther et al., 1999],

$$
\begin{gathered}
E_{o p t}=1.9 \cdot \exp \left(0.125\left(T_{15}-301.0\right)\right) \\
T_{o p t}=316.0+0.5\left(T_{15}-301.0\right) .
\end{gathered}
$$

Figure 15 illustrates the dependence of the monthly mean isoprene emissions, inferred from GOME HCHO columns over the western domain, as a function of the GEOS-4 monthly mean $T(1)$ air temperature used here as a proxy for the current and average leaf temperatures over the past 15 days, $T$ and $T_{15}$ respectively. The data show significant scatter and attempts to fit an exponential curve relating $T(1)$ to GOME isoprene emissions were unsuccessful. Using only data from July-November of each year (nominal dry season) we obtain a more significant relationship with air temperature, although there remain several outliers. We obtain a better fit to the data if we neglect $T_{15}$. Including this 15-day temperature lag yields a stronger exponential dependence that appears more suited to the variation in the average emissions over all months. Fitted $C_{T_{1}}$ and $C_{T_{2}}$ values, using all data, are 64.7 and 58.5, and 176.5 and
166.0, with and without $T_{15}$ respectively. The fitted activation and deactivation energies are therefore smaller and larger than the standard values of Guenther et al. [2006], respectively. The simultaneous fit of $C_{T_{1}}$ and $C_{T_{2}}$ fails to converge using the dry season data (July-November), irrespective of whether the temperature lag is fitted.

[54] Monthly mean isoprene emissions outside of the dry season vary considerably despite only small variations in temperature $(\sim 3 \mathrm{~K})$, suggesting that during these months other factors are responsible for a large percentage of the observed variability. The large variation in the observed wet season emissions is also not explained with variations in PAR; although PAR is higher during the dry season its range of variability is typically the same during the wet and dry months $\left(\sim 25-30 \mathrm{~W} \mathrm{~m}^{-2}\right)$. Previous studies of in situ data over the Amazon have concluded that water availability and changes in leaf physiology and phenology also play a large role in determining isoprene emission [Kuhn et al., 2004a, 2004b] but their relative importance is a subject of continuing study. A recent study using MEGAN, driven at $0.5^{\circ} \times 0.5^{\circ}$ resolution using ECMWF reanalyses, showed that including precipitation and soil moisture activity factors cannot reconcile model and observed isoprene fluxes over the Amazon during the wet season [Müller et al., 2008]. We find no significant correlation with the monthly mean GOME isoprene emissions over western Amazonia with rainfall, PAR or soil moisture (not shown), suggesting that either GOME data are unsuitable (e.g., coarse horizontal resolution, uncertainty) to study these local processes, or that other, possibly nonenvironmental, forcings (e.g., leaf physiology) are driving observed variability.

\section{Reconciling Bottom-Up and Top-Down Isoprene Emission Estimates}

[55] There are notable differences between (1) MEGAN bottom-up isoprene emissions and top-down isoprene emissions inferred from GOME, and (2) GEOS-Chem and observed measurements of isoprene and HCHO. Here, we offer some explanations that might help to reconcile these discrepancies.

[56] Uncertainties in bottom-up isoprene emission models generally arise from errors in emission factors, incorrect and incomplete parameterizations of activity factors, and uncertainties in the driving meteorological fields. As discussed above, emission factors over South America (and in general tropical ecosystems) are particularly uncertain, reflecting a paucity of in situ measurements with which to test and develop models over these region. The use of a single basal emission factor to represent isoprene emission over an entire growing season has already been shown to be inadequate for certain tropical plant species [Kuhn et al., 2004a, 2004b]. The large variation in the top-down isoprene emissions outside the dry season suggest it is determined by external factors other than temperature and light. Improved understanding of plant physiological and phenological changes, and their possible incorporation into MEGAN, represents an avenue where more effort needs to be invested. High biodiversity of tropical ecosystems means that scaling up sparse, detailed point measurements is subject to large errors. A sustained programme of field measurements that catalogue emissions from tropical vegetation is the only 

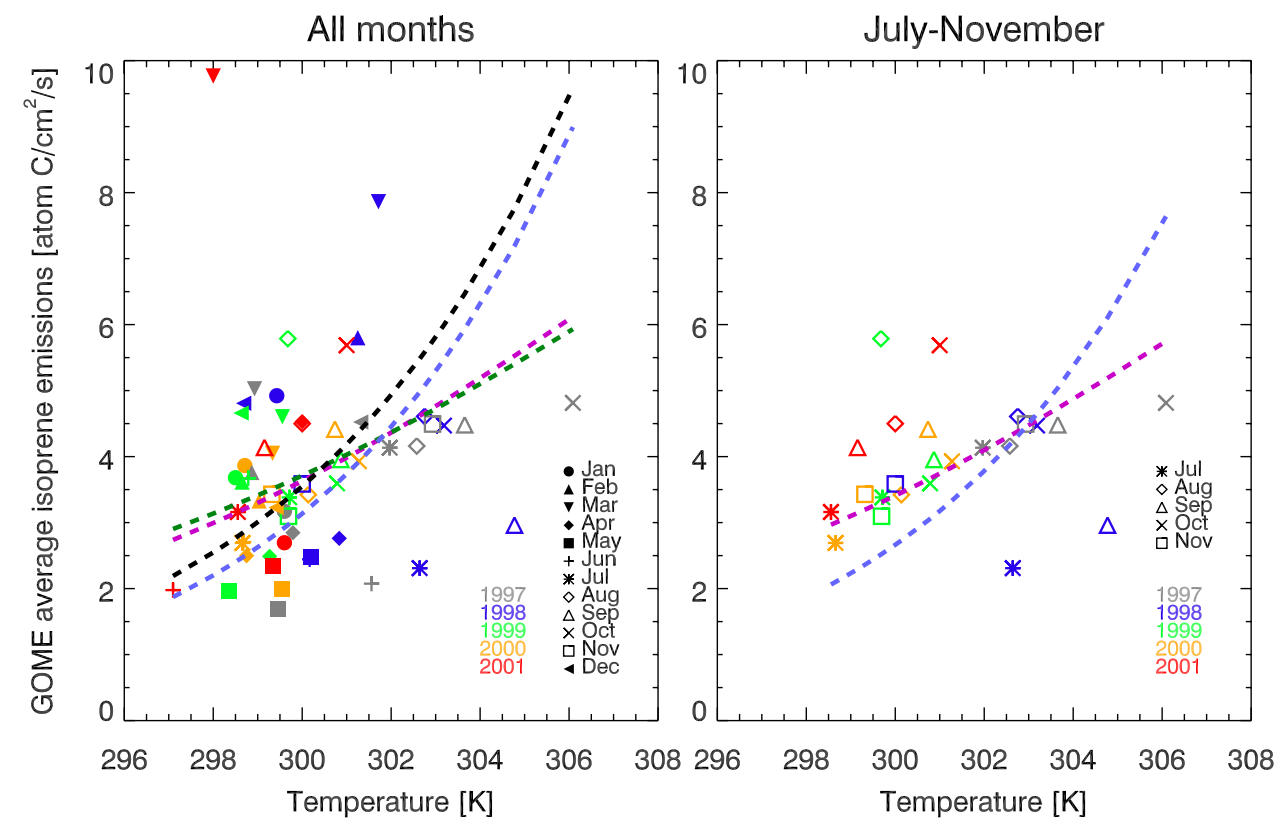

$\begin{array}{ll}\text { Guenther et al, [2006] w/out } T_{15} \text { lag } & \text { Fitted } C_{T 1} \text { and } C_{T 2} \text { w/out } T_{15} \text { lag } \\ \text { Guenther et al, [2006] } T_{15} \text { lag } & \text { Fitted } C_{T 1} \text { and } C_{T 2} \text { with } T_{15} \text { lag }\end{array}$

Figure 15. Scatterplot of the monthly mean isoprene emissions inferred from GOME HCHO columns versus the GEOS-4 air temperature $T(1)$ (at $2 \mathrm{~m}$ height) over the western region for (left) all months and (right) July-November only during 1997-2001. The dashed lines represent fits of equation (8) which describes the relationship between temperature and isoprene emissions parameterized by $\gamma_{T}$ [Guenther et al., 2006]. We fit $\gamma_{T}$ using the $C_{T_{1}}=76$ and $C_{T_{2}}=160$, activation and deactivation energy coefficients, described in section 5.4, both with (light blue line) and without (purple line) the 15-day temperature lag, $T_{15}$. The black and green lines represent an additional simultaneous fit of $C_{T_{1}}$ and $C_{T_{2}}$ to the data, with and without the temperature lag, respectively. Using data from all months the fitted $C_{T_{1}}$ and $C_{T_{2}}$ values are 64.7 and 58.5, and 176.5 and 166.0, with and without $T_{15}$, respectively. The simultaneous fit of $C_{T_{1}}$ and $C_{T_{2}}$ fails to converge during the dry season (July-November), irrespective of whether the temperature lag is fitted.

approach that will rectify gaps in current knowledge. Studies have shown better knowledge of just a few plant species can greatly improve VOC emission estimates in temperate landscapes [Purves et al., 2004].

[57] Uncertainty in top-down isoprene emissions are defined by (1) errors associated with the HCHO column retrievals, including those determined by spectroscopic parameters [Gratien et al., 2007], and instrument design, and (2) uncertainty of the physics and chemistry within and above the forest canopy; here we consider only option 2 .

[58] We find GEOS-Chem tends to overestimate the observed concentrations of isoprene and HCHO over tropical South America. GEOS-Chem has only a basic description of the forest canopy environment (e.g., parameterized radiation model [Guenther et al., 1995]). Within the tropical troposphere, the principal sink of isoprene is oxidation by $\mathrm{OH}$ [Kuhn et al., 2007]; therefore underestimating $\mathrm{OH}$ concentrations will directly affect concentrations of isoprene and HCHO. Recent results by Kuhn et al. [2007] suggest daytime $\mathrm{OH}$ concentrations of $3-8 \times 10^{6}$ molec $\mathrm{cm}^{-3}$ for the early dry season in 2001, derived from observed vertical gradients of isoprene and its primary degradation products; and only very recently the first direct measurements of $\mathrm{OH}$ concentrations over tropical rainforest in Suriname, Guyana and French Guyana became available
[Lelieveld et al., 2008], confirming that isoprene has a considerably smaller effect on $\mathrm{OH}$ depletion than current chemistry models tend to predict. The mean $\mathrm{OH}$ concentrations from the MEGAN v2004 T(1) and GOME simulations (corresponding to $1000-1200 \mathrm{LT}$ ) are $1.8 \times$ $10^{6}$ molec $\mathrm{cm}^{-3}$ and $2.5 \times 10^{6}$ molec cm ${ }^{-3}$ respectively, about a factor of 1.2-4.5 lower than observed values.

[59] Furthermore, for high $\mathrm{OH}$ concentrations (up to $3 \times$ $10^{7}$ molec $\mathrm{cm}^{-3}$ ), oxidation may compete with canopy ventilation as a sink for isoprene and its immediate oxidation products methacrolein (MACR) and methyl vinyl ketone (MVK) [Millet et al., 2007]. Underestimating the $\mathrm{OH}$ sink in the lowest model layers over forested regions will lead to an overestimated regression slope and consequently underestimated isoprene emissions inferred from observed HCHO columns (equation (4)). Although organic peroxides are recycled within the GEOS-Chem chemistry mechanism [Palmer et al., 2003], new studies have suggested $\mathrm{OH}$ may be produced in the recycling process [Butler et al., 2008; Lelieveld et al., 2008]. If true, the extra $\mathrm{OH}$ produced may help to quantitatively reconcile MEGAN and GOME isoprene emission estimates. Recent analysis of MACR and MVK concentration measurements over the Amazon has shown that the within-canopy loss of isoprene from oxidation is about $10 \%$, with the canopy 
ventilation rate much faster than the oxidation loss rate [Kuhn et al., 2007; Karl et al., 2007].

[60] Observed vertical gradients of isoprene within forests show very low near-surface isoprene concentrations [Kuhn et al., 2002], suggesting isoprene uptake at the forest floor. Field and laboratory studies indicate a biological sink of isoprene sink exists within forest soils [Cleveland and Yavitt, 1997, 1998], the magnitude and extent of which remains unknown within tropical ecosystems. The magnitude of a forest soil sink would also be susceptible to environmental forcings, such as drought stress [Pegoraro et al., 2006].

[61] The direct exchange of HCHO between the atmosphere and tropical vegetation is also poorly quantified, though in normal and high ambient aldehyde concentrations trees are most likely to act as sinks [Kondo et al., 1998]. Branch enclosure measurements at the Rebio Jaru ecological reserve, demonstrated aldehyde uptake can occur via leaf stomata and deposition to the leaf cuticles [Rottenberger et al., 2004]. Whilst the branch enclosure measurements also showed direct aldehyde emissions (at low ambient concentrations), deposition of $\mathrm{HCHO}$ was dominant in both wet and dry seasons, suggesting that tropical forests act as a direct sink for HCHO. It is likely that the magnitude of both these sinks, however, may be small in comparison to isoprene and HCHO losses through oxidation and photolysis.

[62] Our simple analysis of net canopy losses of isoprene inferred from GOME, parameterized by the downscaling factor $\rho_{c}$ applied to MEGAN (section 5.2), ranges from 25$44 \%$, is much larger than estimates inferred from in situ measurements [Kuhn et al., 2007; Karl et al., 2007], which may reflect uncertainties in the inference of top-down emissions and the inability of GEOS-Chem to represent in-canopy processes.

\section{Summary}

[63] We have used a 6-year (1997-2001) data set of HCHO columns from the Global Ozone Monitoring Experiment satellite instrument, in conjunction with the MEGAN bottom-up isoprene inventory and the GEOS-Chem CTM, to determine top-down isoprene emission estimates over tropical South America. Bottom-up isoprene emission inventories are particularly poorly quantified over tropical ecosystems, reflecting a sparsity of in situ data, high biodiversity and inaccessibility. Space-borne measurements can help overcome many of these shortcomings.

[64] Inferring isoprene emissions from $\mathrm{HCHO}$ columns over tropical South America is significantly compromised by (1) noise introduced to observed column over southeast South America from the SAA and (2) the source of HCHO from biomass burning. Both of these effects are most pronounced over the eastern parts of the Amazon. For this reason, we focus our study over the western region of South America and extrapolate findings to the eastern regions. We identify and remove measurements compromised by active burning that have been identified using ATSR firecounts and coincident GOME $\mathrm{NO}_{2}$ columns.

[65] In the low $\mathrm{NO}_{\mathrm{x}}$ environment found over tropical ecosystems, we find that isoprene largely determines the observed variability in $\mathrm{HCHO}$ columns, with emissions of $\alpha$ - and $\beta$-pinenes contributing only to the uniform background, reflecting the production of the relatively longlived acetone intermediate. Four different configurations of the GEOS-Chem/MEGAN models have been compared with in situ and aircraft isoprene and $\mathrm{HCHO}$ concentration measurements over the Amazon. In general, model concentrations have a positive bias that may reflect missing incanopy chemistry. Uptake of isoprene by forest soils and direct exchange of $\mathrm{HCHO}$ with vegetation are also possible sink mechanisms that may be underestimated. Of the four model configurations, it was determined that MEGAN v2004 emission factors, driven by the temperature of the first GEOS-Chem model layer, produced the closest match to the in situ measurements. This model, MEGAN v2004 $T(1)$, was subsequently used to determine the transfer function that infers isoprene emissions from observed $\mathrm{HCHO}$ columns.

[66] The resulting seasonal and year-to-year variations in the isoprene emissions inferred from GOME show that the highest-emitting region is consistently the Amazon basin within western Brazil. The emissions peak during the dry season (August-November) and lower in the wet season. In the dry season, inferred emissions are consistent with the temperature dependence predicted by MEGAN. Outside the dry season, other factors appear to also play a large role in determining observed variability, however, we have not been able to identify a significant correlation with likely factors such as precipitation or soil moisture.

[67] In general, GOME isoprene emissions are lower than those predicted by MEGAN, reflecting partly that GOME estimates represent net ecosystem fluxes while MEGAN predicts leaf-level canopy emissions. Crudely accounting for net above and within-canopy losses, requires MEGAN v2004 T(1) isoprene emissions to be reduced by $33 \%$. Differences between GOME and MEGAN can also be attributed to errors in the $\mathrm{HCHO}$ column retrieval and to errors associated with the chemistry mechanism that determines the transfer function. We calculate the total error associated with GOME isoprene emissions to be of order $100 \%$.

[68] Future work will focus on using $\mathrm{HCHO}$ column data from newer space-borne sensors that have 40 times better spatial resolution and daily coverage, for example, OMI aboard NASA's Aura satellite and GOME-2 aboard the European MetOp platform. Using these sensors will (1) increase the number of cloud-free scenes that will improve the signal-to-noise of averaged quantities; (2) improve the differentiation between biogenic and pyrogenic sources of $\mathrm{HCHO}$; and (3) broaden the process studies that can be achieved. A greater number of observations permits better spatially resolved transfer functions [e.g., Millet et al., 2007]. However, as isoprene takes approximately an hour to produce $(1-1 / \mathrm{e})$ of its ultimate $\mathrm{HCHO}$ yield, its average smearing length is about $100 \mathrm{~km}$ [Palmer et al., 2003]. Therefore, despite the higher resolution of new sensors $100 \mathrm{~km}$ may represent the spatial limit for inferring top-down isoprene emissions estimates using the linear regression approach, beyond which a more formal inversion scheme would be required [Palmer et al., 2007].

[69] Acknowledgments. This work was supported by the National Environment Research Council (NERC research grant NE/D001471). The 
authors would like to thank Tzung-May Fu, Dylan Millet, and Robert Yantosca for useful help and advice. The GEOS-Chem model is managed at Harvard University with support from the NASA Atmospheric Chemistry Modelling and Analysis Program. The authors would also like to thank Kamel Didan and Alfredo Huete for providing the EVI data and the ESA portal for providing the ATSR firecounts.

\section{References}

Abbot, D. S., P. I. Palmer, R. V. Martin, K. V. Chance, D. J. Jacob, and A. Guenther (2003), Seasonal and interannual variability of North American isoprene emissions as determined by formaldehyde column measurements from space, Geophys. Res. Lett., 30(17), 1886 , doi:10.1029/2003GL017336.

Andreae, M. O., and P. J. Crutzen (1997), Atmospheric aerosols: Biogeochemical sources and role in atmospheric chemistry, Science, 276 , 1052 - 1058, doi:10.1126/science.276.5315.1052.

Andreae, M. O., and P. Merlet (2001), Emission of trace gases and aerosols from biomass burning, Global Biogeochem. Cycles, 15(4), 955-966, doi:10.1029/2000GB001382.

Andreae, M. O., et al. (2002), Biogeochemical cycling of carbon, water, energy, trace gases, and aerosols in Amazonia: The LBA-EUSTACH experiments, J. Geophys. Res., 107(D20), 8066, doi:10.1029/2001JD000524.

Balkanski, Y. J., D. J. Jacob, G. M. Gardiner, W. C. Graustein, and K. K. Turekian (1993), Transport and residence times of tropospheric aerosol inferred from a gloal three-dimensional simulation of ${ }^{210} \mathrm{~Pb}$ J. Geophys. Res., 98(D11), 20,573-20,586, doi:10.1029/93JD02456.

Bey, I., et al. (2001), Global modeling of tropospheric chemistry with assimilated meteorology: Model description and evaluation, J. Geophys. Res., 106(D19), 23,073-23,096, doi:10.1029/2001JD000807.

Bloss, C., et al. (2005), Development of a detailed chemical mechanism (MCMv3.1) for the atmospheric oxidation of aromatic hydrocarbons, Atmos. Chem. Phys., 5, 641-664.

Burrows, J. P., et al. (1999), The Global Ozone Monitoring Experiment (GOME): Mission concept and first scientific results, J. Atmos. Sci., 56, $151-175$.

Butler, T. M., D. Taraborrelli, C. Brühl, H. Fischer, H. Harder, M. Martinez, J. Williams, M. G. Lawrence, and J. Lelieveld (2008), Improved simulation of isoprene oxidation chemistry with the ECHAM5/MESSy chemistry-climate model: Lessons from the GABRIEL airborne field campaign, Atmos. Chem. Phys., 8, 4529-4546.

Chance, K., P. I. Palmer, R. J. D. Spurr, R. V. Martin, T. P. Kurosu, and D. J. Jacob (2000), Satellite observations of formaldehyde over North America from GOME, Geophys. Res. Lett., 27(21), 3461-3464, doi:10.1029/2000GL011857.

Claeys, M., et al. (2004), Formation of secondary organic aerosols through photooxidation of isoprene, Science, 303, 1173-1176, doi:10.1126/ science. 1092805 .

Cleveland, C. C., and J. B. Yavitt (1997), Consumption of atmospheric isoprene in soil, Geophys. Res. Lett., 24(19), 2379-2382, doi:10.1029/ 97GL02451.

Cleveland, C. C., and J. B. Yavitt (1998), Microbial consumption of atmospheric isoprene in a temperate forest soil, Appl. Environ. Microbiol., 64(1), 172-177.

da Rocha, H. R., M. L. Goulden, S. D. Miller, M. C. Menton, L. D. V. O Pinto, H. C. de Freitas, and A. M. S. Figueira (2004), Seasonality of water and heat fluxes over a tropical forest in eastern Amazonia, Ecol. Appl., 14(4), supplement, S22-S32.

Davis, K. J., D. H. Lenschow, and P. R. Zimmerman (1994), Biogenic nonmethane hydrocarbon emissions estimated from tethered balloon observations, J. Geophys. Res., 99(D12), 25,587-25,598, doi:10.1029/ 94JD02009.

Fiore, A. M., D. J. Jacob, I. Bey, R. M. Yantosca, B. D. Field, and J. G. Wilkinson (2002), Background ozone over the United States in summer: Origin and contribution to pollution episodes, J. Geophys. Res., 107(D15), 4275, doi:10.1029/2001JD000982.

Fu, T.-M., D. J. Jacob, P. I. Palmer, K. Chance, Y. X. Wang, B. Barletta, D. R. Blake, J. C. Stanton, and M. J. Pilling (2007), Space-based formaldehyde measurements as constraints on volatile organic compound emissions in east and south Asia and implications for ozone, J. Geophys. Res., 112, D06312, doi:10.1029/2006JD007853.

Giglio, L., J. Descloitres, C. O. Justice, and Y. J. Kaufman (2003), An enhanced contextual fire detection algorithm for MODIS, Remote Sens. Environ., 87(2-3), 273-282.

Giglio, L., G. R. van der Werf, J. T. Randerson, G. J. Collatz, and P. Kasibhatla (2006), Global estimation of burned area using MODIS active fire observations, Atmos. Chem. Phys., 6, 957-974.

Gratien, A., B. Picquet-Varrault, J. Orphal, E. Perraudin, J.-F. Doussin, and J.-M. Flaud (2007), Laboratory intercomparison of the formaldehyde absorption cross sections in the infrared $\left(1660-1820 \mathrm{~cm}^{-1}\right)$ and ultra- violet (300-360 nm) spectral regions, J. Geophys. Res., 112, D05305, doi:10.1029/2006JD007201.

Greenberg, J. P., A. Guenther, G. Pétron, C. Wiedinmeyer, O. Vega, L. V. Gatti, J. Tota, and G. Fisch (2004), Biogenic VOC emissions from forested Amazonian landscapes, Global Change Biol., 10, 651-662, doi:10.1111/j.1529-8817.2003.00758.x.

Guenther, A., et al. (1995), A global model of natural volatile organic compound emissions, J. Geophys. Res., 100(D5), 8873-8892, doi:10.1029/94JD02950.

Guenther, A., B. Baugh, G. Brasseur, J. Greenberg, P. Harley, L. Klinger, D. Serça, and L. Vierling (1999), Isoprene emission estimates and uncertainties for the Central African EXPRESSO study domain, J. Geophys. Res., 104(D23), 30,625-30,639.

Guenther, A., T. Karl, P. Harley, C. Wiedinmyer, P. I. Palmer, and C. Geron (2006), Estimates of global terrestrial isoprene emissions using MEGAN (Model of Emissions of Gases and Aerosols from Nature), Atmos. Chem. Phys., 6, 3181-3210.

Heirtzler, J. R. (2002), The future of the South Atlantic anomaly and implications for radiation damage in space, J. Atmos. Sol. Terr. Phys. 64(16), 1701-1708.

Helmig, D., et al. (1998), Vertical profiling and determination of landscape fluxes of biogenic non-methane hydrocarbons within the planetary boundary layer in the Peruvian Amazon, J. Geophys. Res., 103(D19), 25,519-25,532, doi:10.1029/98JD01023.

Henze, D. K., and J. H. Seinfeld (2006), Global secondary organic aerosol from isoprene oxidation, Geophys. Res. Lett., 33, L09812, doi:10.1029/ 2006GL025976.

Hirsch, R. M., and E. J. Gilroy (1984), Methods of fitting a straight line to data: Examples in water resources, Water Resour. Bull., 20, 705-711.

Horowitz, L. W., J. Liang, G. M. Gardner, and D. J. Jacob (1998), Export of reactive nitrogen from North America during summertime: Sensitivity to hydrocarbon chemistry, J. Geophys. Res., 103(D11), 13,451-13,476, doi:10.1029/97JD03142.

Huete, A., K. Didan, T. Miura, E. P. Rodriguez, X. Gao, and L. G. Ferreira (2002), Overview of the radiometric and biophysical performance of the MODIS vegetation indices, Remote Sens. Environ., 83(1-2), 195-213.

Huete, A. R., K. Didan, Y. E. Shimabukuro, P. Ratana, S. R. Saleska, L. R. Hutyra, W. Yang, R. R. Nemani, and R. Myneni (2006), Amazon rainforests green-up with sunlight in dry season, Geophys. Res. Lett., 33 , L06405, doi:10.1029/2005GL025583.

Jacob, D. J., and P. S. Bakwin (1992), Cycling of $\mathrm{NO}_{\mathrm{x}}$ in tropical forest canopies, in Microbial Production and Consumption of Greenhouse Gases, edited by W. B. Whitman, pp. 237-253, Am. Soc. of Microbiol., Washington D. C

Jacob, D. J., and S. C. Wofsy (1988), Photochemistry of biogenic emissions over the Amazon Forest, J. Geophys. Res., 93(D2), 1477-1486, doi:10.1029/88JD01582.

Jaeglé, L., L. Steinberger, R. V. Martin, and K. Chance (2005), Global partitioning of $\mathrm{NO}_{x}$ sources using satellite observations: Relative roles of fossil fuel combustion, biomass burning and soil emissions, Faraday Discuss., 130, 407-423, doi:10.1039/b502128f.

Justice, C. O., et al. (1998), The Moderate Resolution Imaging Spectroradiometer (MODIS): Land remote sensing for global change research, IEEE Trans. Geosci. Remote Sens., 36, 1228-1249.

Karl, T., A. Guenther, R. J. Yokelson, J. Greenberg, M. Potosnak, D. R. Blake, and P. Artaxo (2007), The tropical forest and fire emissions experiment: Emission, chemistry, and transport of biogenic volatile organic compounds in the lower atmosphere over Amazonia, J. Geophys. Res., 112, D18302, doi:10.1029/2007JD008539.

Kesselmeier, J. (2004), Interactive comment on "Seasonal cycles of isoprene concentrations in the Amazonian rainforest" by C. R. Trostdorf et al., Atmos. Chem. Phys. Discuss., 4, S528-S530.

Kesselmeier, J., et al. (2000), Atmospheric volatile organic compounds (VOC) at a remote tropical forest site in central Amazonia, Atmos. Environ., 34(24), 4063-4072.

Kesselmeier, J., et al. (2002a), Volatile organic compound emissions in relation to plant carbon fixation and the terrestrial carbon budget, Global Biogeochem. Cycles, 16(4), 1126, doi:10.1029/2001GB001813.

Kesselmeier, J., et al. (2002b), Concentrations and species composition of atmospheric volatile organic compounds (VOCs) as observed during the wet and dry season in Rondônia (Amazonia), J. Geophys. Res., 107(D20), 8053, doi:10.1029/2000JD000267.

Koelemeijer, R. B. A., J. F. de Haan, and P. Stammes (2003), A database of spectral surface reflectivity of the Earth in the range 335-772 nm derived from 5.5 years of GOME observations, J. Geophys. Res., 108(D2), 4070, doi:10.1029/2002JD002429.

Kondo, T., K. Hasegawa, R. Uchida, and M. Onishi (1998), Absorption of atmospheric $\mathrm{C}_{2}-\mathrm{C}_{5}$ aldehydes by various tree species and their tolerance to $\mathrm{C}_{2}-\mathrm{C}_{5}$ aldehydes, Sci. Total Environ., 224, 121-132. 
Kuhn, U., et al. (2002), Isoprene and monoterpene emissions of Amazônian tree species during the wet season: Direct and indirect investigations on controlling environmental functions, J. Geophys. Res., 107(D20), 8071, doi:10.1029/2001JD000978.

Kuhn, U., S. Rottenberger, T. Biesenthal, A. Wolf, G. Schebeske, P. Ciccioli, and J. Kesselmeier (2004a), Strong correlation between isoprene emission and gross photosynthetic capacity during leaf phenology of the tropical tree species Hymenaea courbaril with fundamental changes in volatile organic compounds emission composition during early leaf development, Plant Cell Environ., 27, 1469-1485.

Kuhn, U., et al. (2004b), Seasonal differences in isoprene and lightdependent monoterpene emission by Amazonian tree species, Global Change Biol., 10, 663-682, doi:10.1111/j.1529-8817.2003.00771.x.

Kuhn, U., et al. (2007), Isoprene and monoterpene fluxes from central Amazonian rainforest inferred from tower-based and airborne measurements, and implications on the atmospheric chemistry and the local carbon budget, Atmos. Chem. Phys., 7, 2855-2879.

Kurosu, T. P., K. Chance, and R. J. D. Spurr (1999), CRAG-Cloud Retrieval Algorithm for ESA's Global Ozone Monitoring Experiment, paper presented at European Symposium on Atmospheric Measurements From Space, Eur. Space Agency, Noordwijk, Netherlands.

Lathière, J., D. A. Hauglustaine, A. Friend, N. De Noblet-Ducoudré, N. Viovy, and G. Folberth (2006), Impact of climate variability and land use changes on global biogenic volatile organic compound emissions, Atmos. Chem. Phys., 6, 2129-2146.

Lee, M., B. G. Heikes, and D. J. Jacob (1998), Enhancements of hydroperoxides and formaldehyde in biomass burning impacted air and their effect on atmospheric oxidant cycles, J. Geophys. Res., 103(D11), 13,201-13,212, doi:10.1029/98JD00578

Lelieveld, J., et al. (2008), Atmospheric oxidation capacity sustained by a tropical forest, Nature, 452, 737-740, doi:10.1038/nature06870.

Liebmann, B., and J. A. Marengo (2001), Interannual Variability of the rainy season and rainfall in the Brazilian Amazon Basin, J. Clim., 14, $4308-4318$

Martin, R. V., et al. (2002), An improved retrieval of tropospheric nitrogen dioxide from GOME, J. Geophys. Res., 107(D20), 4437, doi:10.1029/ 2001JD001027.

Martin, R. V., D. J. Jacob, K. Chance, T. P. Kurosu, P. I. Palmer, and M. J. Evans (2003), Global inventory of nitrogen oxide emissions constrained by space-based observations of $\mathrm{NO}_{2}$ columns, J. Geophys. Res., 108(D17), 4537, doi:10.1029/2003JD003453.

Millet, D. B., et al. (2006), Formaldehyde distribution over North America: Implications for satellite retrievals of formaldehyde columns and isoprene emission, J. Geophys. Res., 111, D24S02, doi:10.1029/2005JD006853.

Millet, D. B., D. J. Jacob, K. Folkert Boersma, T.-M. Fu, T. P. Kurosu, K. Chance, C. L. Heald, and A. Guenther (2007), Spatial distribution of isoprene emissions from North America dervied from formaldehyde column measurements by the OMI satellite sensor, J. Geophys. Res., 113, D02307, doi:10.1029/2007JD008950.

Monson, R. K., and E. A. Holland (2001), Bisopheric trace gas fluxes and their control over tropospheric chemsitry, Annu. Rev. Ecol. Syst., 32, $547-576$.

Mota, B. W., J. M. C. Pereira, D. Oom, M. J. P. Vasconcelos, and M. Schultz (2006), Screening the ESA ATSR-2 World Fire Atlas (1997-2002), Atmos. Chem. Phys., 6, 1409-1424.

Müller, J.-F., et al. (2008), Global isoprene emissions estimated using MEGAN, ECMWF analyses and a detailed canopy environment model, Atmos. Chem. Phys., 8, 1329-1341.

Myneni, R. B., R. R. Nemani, and S. W. Running (1997), Estimation of global leaf area index and absorbed PAR using radiative transfer models, IEEE Trans. Geosci. Remote Sens., 35, 1380-1393.

Nepstad, D. C., C. R. de Carvalho, E. A. Davidson, P. Jipp, P. Lefebvre, G. H. Negreiros, E. D. da Silva, S. T. T. Stone, and S. Vieira (1994), The role of deep roots in the hydrological and carbon cycles of Amazonian forests and pastures, Nature, 372, 666-669, doi:10.1038/372666a0.

Palmer, P. I., et al. (2001), Air mass factor formulation for spectroscopic measurements from satellites: Application to formaldehyde retrievals from the Global Ozone Monitoring Experiment, J. Geophys. Res. 106(D13), 14,539-14,550, doi:10.1029/2000JD900772.

Palmer, P. I., D. J. Jacob, A. M. Fiore, R. V. Martin, K. Chance, and T. P. Kurosu (2003), Mapping isoprene emissions over North America using formaldehyde column observations from space, J. Geophys. Res., 108(D6), 4180, doi:10.1029/2002JD002153.

Palmer, P. I., et al. (2006), Quantifying the seasonal and interannual variability of North American isoprene emissions using satellite observations of formaldehyde column, J. Geophys. Res., 111, D12315, doi:10.1029/ 2005JD006689.

Palmer, P. I., M. P. Barkley, T. P. Kurosu, A. C. Lewis, J. E. Saxton, K. Chance, and L. V. Gatti (2007), Interpreting satellite column observa- tions of formaldehyde over tropical South America, Philos. Trans. R. Soc., Ser. A, 365, 1741-1751.

Park, R. J., D. J. Jacob, B. D. Field, R. M. Yantosca, and M. Chin (2004), Natural and transboundary pollution influences on sulfatenitrate-ammonium aerosols in the United States: Implications for policy, J. Geophys. Res., 109, D15204, doi:10.1029/2003JD004473.

Pegoraro, E., A. Rey, L. Abrell, J. Haren, and G. Lin (2006), Drought effect on isoprene production and consumption in Biosphere 2 tropical rainforest, Global Change Biol., 12, 456-469, doi:10.1111/j.1365-2486. 2006.01112x.

Poisson, N., M. Kanakidou, and P. J. Crutzen (2000), Impact of nonmethane hydrocarbons on tropospheric chemsitry and the oxidizing power of the global troposphere: 3-dimensional modelling results, J. Atmos. Chem., 36, 157-230, doi:10.1023/A:1006300616544.

Potter, C. S., J. T. Randerson, C. B. Field, P. A. Matson, P. M. Vitousek, H. A. Mooney, and S. A. Klooster (1993), Terrestrial ecosystem production: A process model based on global satellite and surface data, Global Biogeochem. Cycles, 7(4), 811-841, doi:10.1029/93GB02725.

Potter, C. S., S. E. Alexander, J. C. Coughlan, and S. A. Klooster (2001), Modeling biogenic emissions of isoprene: exploration of model drivers, climate control algorithms, and use of global satellite observations, Atmos. Environ., 35(35), 6151-6165.

Purves, D. W., J. P. Caspersen, P. R. Moorcroft, G. C. Hurt, and S. W. Pacala (2004), Human-induced changes in US biogenic volatile organic compound emissions: evidence from long-term forest inventory data, Global Change Biol., 10, 1737-1755, doi:10.1111/j.1365-2486.2004.00844.x.

Rasmussen, R. A., and M. A. K. Khalil (1988), Isoprene over the Amazon Basin, J. Geophys. Res., 93(D2), 1417-1421, doi:10.1029/88JD01577.

Richter, A., and T. Wagner (2001), Diffuser plate spectral structures and their influence on GOME slant columns, technical report, Inst. Environ. Phys., Univ. Bremen, Bremen, Germany.

Rinne, H. J., A. B. Guenther, J. P. Greenberg, and P. C. Harley (2002), Isoprene and monoterpene fluxes measured above the Amazonian rainforest and their dependence on light and temperature, Atmos. Environ., 36(14), 2421-2426.

Rottenberger, S., U. Kuhn, A. Wolf, G. Schebeske, S. T. Oliva, M. Tavares, and J. Kesselmeier (2004), Exchange of short-chain aldehydes between Amazonian vegetation and the atmosphere, Ecol. Appl., 14(4), supplement, 247-262.

Saleska, S. R., K. Didan, A. R. Huete, and H. R. da Rocha (2007), Amazon Forests green-up during 2005 drought, Science, 318, 612, doi:10.1126/ science. 1146663 .

Sanderson, M. G., C. D. Jones, W. J. Collins, C. E. Johnson, and R. G. Derwent (2003), Effect of climate change on isoprene emissions and surface ozone levels, Geophys. Res. Lett., 30(18), 1936, doi:10.1029/ 2003GL017642.

Schubert, S. D., R. B. Rood, and J. Pfaendtner (1993), An assimilated dataset for Earth science applications, Bull. Am. Meteorol. Soc., 74, $2331-2342$

Shim, C., Y. Wang, Y. Choi, P. I. Palmer, D. S. Abbot, and K. Chance (2005), Constraining global isoprene emissions with Global Ozone Monitoring Experiment (GOME) formaldehyde column measurements, J. Geophys. Res., 110, D24301, doi:10.1029/2004JD005629.

Singsaas, E. L., and T. D. Sharkey (2000), The effects of high temperature on isoprene synthesis in oak leaves, Plant Cell Environ., 23(7), 751-757, doi:10.1046/j.1365-3040.2000.00582.x.

Spurr, R. J. D., T. P. Kurosu, and K. Chance (2001), A linearized discrete ordinate radiative transfer model for atmospheric remote sensing retrieval, J. Quant. Spectrosc. Radiat. Transfer, 68(6), 689-735.

Stassinopoulos, E. G., and J. P. Raymond (1988), The space radiation environment for electronics, Proc. IEEE, 76(11), 1423-1442, doi:10.1109/5. 90113.

Trostdorf, C. R., L. V. Gatti, A. Yamazaki, M. J. Potosnak, A. Guenther, W. C. Martins, and J. W. Munger (2004), Seasonal cycles of isoprene concentrations in the Amazonian rainforest, Atmos. Chem. Phys. Discuss. 4, $1291-1310$.

van der Werf, G. R., J. T. Randerson, L. Giglio, G. J. Collatz, P. S. Kasibhatla, and A. F. Arellano Jr. (2006), Interannual variability in global biomass burning emissions from 1997 to 2004, Atmos. Chem. Phys., 6, 3423-3441.

Wang, K. Y., and D. E. Shallcross (2000), Modelling terrestrial biogenic isoprene fuxes and their potential impact on global chemical species using a coupled LSM-CTM model, Atmos. Environ., 34, 2909-2925.

Yokelson, R. J., R. Susott, D. E. Ward, J. Reardon, and D. W. T. Griffith (1997), Emissions from smoldering combustion of biomass measured by open-path Fourier transform infrared spectroscopy, J. Geophys. Res., 102(D15), 18,865-18,878

Zimmerman, P. R., J. P. Greenberg, and C. E. Westberg (1988), Measurements of atmospheric hydrocarbons and biogenic emission fluxes in the 
Amazon Boundary Layer, J. Geophys. Res., 93(D2), 1407-1416, doi:10.1029/88JD01576.

M. P. Barkley and P. I. Palmer, School of GeoSciences, University of Edinburgh, King's Buildings, West Mains Road, Edinburgh EH9 3JN, UK. (michael.barkley@ed.ac.uk; pip@ed.ac.uk)

K. Chance and T. P. Kurosu, Atomic and Molecular Physics Division, Harvard-Smithsonian Center for Astrophysics, 60 Garden Street, Cambridge, MA 02138-1516, USA. (kchance@cfa.harvard.edu; tkurosu@ cfa.harvard.edu)

A. Guenther, Biosphere-Atmosphere Interactions Group, Atmospheric Chemistry Division, NCAR, 1850 Table Mesa Drive, Boulder, CO 80307 , USA. (guenther@ucar.edu)
D. Helmig, INSTAAR, University of Colorado, 1560 30th Street, Boulder, CO 80309-0450, USA. (detlev@instaar.colorado.edu)

J. Kesselmeier, Biogeochemistry Department, Max Planck Institute for Chemistry, P.O. Box 3060, D-55020 Mainz, Germany. (jks@mpchmainz.mpg.de)

U. Kuhn, Agroscope Reckenholz-Taenikon Research Station, Reckenholzstrasse 191, CH-8046 Zurich, Switzerland. (kuhn@mpchmainz.mpg.de)

R. V. Martin, Department of Physics and Atmospheric Science, Dalhousie University, Sir James Dunn Building, Halifax, NS B3H 3J5, Canada. (randall.martin@dal.ca) 